\title{
A Unified Approach to Taxonomic Delimitation in the Fern Genus Pentagramma (Pteridaceae)
}

\author{
Author(s): Eric Schuettpelz, Kathleen M. Pryer, and Michael D. Windham
}

Source: Systematic Botany, 40(3):629-644.

Published By: The American Society of Plant Taxonomists

URL: http://www.bioone.org/doi/full/10.1600/036364415X689366

BioOne (www.bioone.org) is a nonprofit, online aggregation of core research in the biological, ecological, and environmental sciences. BioOne provides a sustainable online platform for over 170 journals and books published by nonprofit societies, associations, museums, institutions, and presses.

Your use of this PDF, the BioOne Web site, and all posted and associated content indicates your acceptance of BioOne's Terms of Use, available at www.bioone.org/page/terms_of_use.

Usage of BioOne content is strictly limited to personal, educational, and non-commercial use. Commercial inquiries or rights and permissions requests should be directed to the individual publisher as copyright holder. 
Systematic Botany (2015), 40(3): pp. 629-644

(c) Copyright 2015 by the American Society of Plant Taxonomists

DOI $10.1600 / 036364415 \times 689366$

Date of publication September 22, 2015

\title{
A Unified Approach to Taxonomic Delimitation in the Fern Genus Pentagramma (Pteridaceae)
}

\author{
Eric Schuettpelz, ${ }^{1,3}$ Kathleen M. Pryer, ${ }^{2}$ and Michael D. Windham ${ }^{2}$ \\ ${ }^{1}$ Department of Botany, National Museum of Natural History, Smithsonian Institution, PO Box 37012, Washington, \\ District of Columbia 20013, U. S. A. \\ ${ }^{2}$ Department of Biology, Duke University, Durham, North Carolina 27708, U. S. A. \\ ${ }^{3}$ Author for correspondence (schuettpelze@si.edu) \\ Communicating Editor: Mark P. Simmons
}

\begin{abstract}
The native goldback and silverback ferns of western North America, composing the genus Pentagramma, are phylogenetically isolated within the xeric-adapted cheilanthoid clade. Although species-poor compared to its sister group, Pentagramma encompasses a diverse array of morphotypes, cytotypes, and flavonoid chemotypes. Because the differences are generally cryptic, however, the various entities are usually recognized at an infraspecific level. In recent years, as many as five subspecies have been ascribed to P. triangularis, and only $P$. pallida has been considered sufficiently divergent to warrant recognition as a distinct species. In this study, we take a unified approach to taxonomic delimitation in Pentagramma. Combining spore studies with phylogenetic analyses of plastid and nuclear sequences, we identify six genetically and morphologically distinct diploid lineages, each of which is here treated as a species. A new species is described ( $\boldsymbol{P}$. glanduloviscida) and three new combinations are made ( $\boldsymbol{P}$. maxonii, $\boldsymbol{P}$. rebmanii, and $\boldsymbol{P}$. viscosa).
\end{abstract}

Keywords-California floristic province, goldback ferns, low-copy nuclear gene, polyploidy, silverback ferns, Sonoran desert.

Although once placed in the pantropical pteridoid genus Pityrogramma, the goldback and silverback ferns of western North America are now resolved within the xeric-adapted cheilanthoid lineage, in an altogether different part of the Pteridaceae phylogeny (Schuettpelz et al. 2007). Among cheilanthoids, these ferns occupy a rather isolated phylogenetic position (Gastony and Rollo 1998; Eiserhardt et al. 2011) and their treatment as a distinct genus, Pentagramma (Yatskievych et al. 1990), is clearly warranted. Pentagramma is sister to all other members of the hemionitid clade sensu Windham et al. (2009), and is estimated to have diverged about 26 million years ago (Schuettpelz and Pryer 2009). Yet, despite its considerable age, the genus today only accounts for a handful of taxa inhabiting a relatively narrow geographic range. This contrasts sharply with the success of its sister group, which includes more than 250 species distributed throughout the drier areas of the globe (Windham et al. 2009). Its rather minor contribution to global fern diversity notwithstanding, Pentagramma has been the focus of considerable taxonomic study over the past century (Weatherby 1920; Alt and Grant 1960; Smith 1980; Yatskievych et al. 1990; Winner and Simpson 2007).

The first of the various taxa now ascribed to Pentagramma was published by Kaulfuss (1824) as Gymnogramma triangularis (Table 1). More than half a century passed before a second taxon, Gymnogramma triangularis var. viscosa, was formally recognized (Eaton 1879). Both were treated as distinct species by Maxon (1913), who called them Pityrogramma triangularis and $P$. viscosa, respectively. In the first focused study of the group, Weatherby (1920, p. 113) noted four "distinguishable extremes", but argued that they were "separated by characters either too slight in themselves or too little constant to warrant their segregation as species". Weatherby thus chose to treat these four entities as varieties of Pityrogramma triangularis (var. triangularis, var. viscosa, var. maxonii, and var. pallida). Alt and Grant (1960) recognized the same four taxa, but elevated two varieties (var. viscosa and var. pallida) to species ( $P$. viscosa and P. pallida). A fifth taxon (P. triangularis var. semipallida) was subsequently described by Howell (1962), and later accepted by Smith (1980) in his treatment of the genus. Smith, however, recognized just two species, $P$. pallida and $P$. triangularis, the latter with four varieties (var. triangularis, var. viscosa, var. maxonii, and var. semipallida; Table 1).

Finding the native goldback and silverback ferns of western North America to be morphologically and cytogenetically isolated from the remainder of Pityrogramma, Yatskievych et al. (1990) transferred them to a new genus, Pentagramma (Table 1). They followed Smith (1980) in recognizing two species ( $P$. pallida and P. triangularis) and treated the four morphological extremes of the latter as subspecies (rather than varieties). Recently, Winner and Simpson (2007) described an additional (fifth) subspecies of $P$. triangularis (subsp. rebmanii).

Previous taxonomic classifications of the goldback and silverback ferns of western North America have relied on characteristics such as the distribution and color of powdery excretions (farina) and the presence or absence of glands or a resinous exudate on adaxial leaf surfaces. Following the most recent treatment (Winner and Simpson 2007), the leaves of Pentagramma triangularis subsp. triangularis are abaxially yellow farinose and adaxially glabrous. The remaining taxa are all abaxially white farinose, but differ in their adaxial surfaces. Like subsp. triangularis, subsp. semipallida is adaxially glabrous. The adaxial leaf surfaces of subsp. maxonii are glandular and those of subsp. viscosa are viscid. Pentagramma pallida and $P$. triangularis subsp. rebmanii are both adaxially white farinose; however, while the adaxial farina of $P$. pallida is so dense as to obscure the lamina, it is sparse in subsp. rebmanii. Throughout this paper, we will generally refer to the aforementioned species and subspecies (sensu Winner and Simpson 2007) as morphotypes (six in total), each designated with a single letter $(\mathrm{M}=P$. triangularis subsp. maxonii; $\mathrm{P}=$ P. pallida; $\mathrm{R}=P$. triangularis subsp. rebmanii; $\mathrm{S}=P$. triangularis subsp. semipallida; $\mathrm{T}=P$. triangularis subsp. triangularis; $\mathrm{V}=$ $P$. triangularis subsp. viscosa). This is done for simplicity, but also, following the precedent of Alt and Grant (1960) in their use of uninomials, serves to indicate the uncertain taxonomic status of these entities and ultimately avoids confusion with our taxonomic conclusions.

Although Pentagramma has been the subject of numerous morphological, cytological, and phytochemical studies (Alt 
TABLE 1. Key taxonomic treatments of the goldback and silverback ferns of western North America. Specific and infraspecific epithets are abbreviated: $t=$ triangularis; $v=$ viscos $a ; m=$ maxonii; $p=$ pallida $s=$ semipallida $r=$ rebmanii $g=$ glanduloviscida.

\begin{tabular}{|c|c|c|c|c|c|c|c|c|}
\hline Kaulfuss (1824) & Eaton (1879) & Maxon (1913) & Weatherby (1920) & Alt and Grant (1960) & Smith (1980) & $\begin{array}{c}\text { Yatskievych et al. } \\
\text { (1990) }\end{array}$ & $\begin{array}{l}\text { Winner and Simpson } \\
\text { (2007) }\end{array}$ & This study \\
\hline Gymnogramma & Gymnogramma & Pityrogramma & Pityrogramma & Pityrogramma & Pityrogramma & Pentagramma & Pentagramma & Pentagramma \\
\hline$t$ & $t$ var. $t$ & $t$ & $t$ var. $t$ & $t$ var. $t$ & $t$ var. $t$ & $t$ subsp. $t$ & $t$ subsp. $t$ & $t$ \\
\hline- & $t$ var. $v$ & $v$ & $t$ var. $v$ & $v$ & $t$ var. $v$ & $t$ subsp. $v$ & $t$ subsp. $v$ & $v$ \\
\hline- & - & - & $t$ var. $m$ & $t$ var. $m$ & $t$ var. $m$ & $t$ subsp. $m$ & $t$ subsp. $m$ & $m$ \\
\hline- & - & - & $t$ var. $p$ & $p$ & $p$ & $p$ & $p$ & $p$ \\
\hline- & - & - & - & - & $t$ var. $s$ & $t$ subsp. $s$ & $t$ subsp. $s$ & - \\
\hline- & - & - & - & - & - & - & $t$ subsp. $r$ & $r$ \\
\hline- & - & - & - & - & - & - & - & $g$ \\
\hline
\end{tabular}

and Grant 1960; Smith et al. 1971; Wollenweber et al. 1979; Smith 1980; Wollenweber and Dietz 1980; Wollenweber and Smith 1981; Wollenweber et al. 1985; Yatskievych et al. 1990; Windham and Yatskievych 2003; Winner and Simpson 2007), the genus has yet to be evaluated from a molecularphylogenetic perspective. In this study, we employ nuclear and plastid DNA sequencing to reveal phylogenetic relationships within Pentagramma. Incorporating spore measurements calibrated by chromosome counts to infer ploidy, we then identify genetically distinct diploid lineages, test previous hypotheses of specific and infraspecific delimitation, and investigate the origins of polyploid individuals. We summarize our findings in a revised classification for these ferns.

\section{Materials ANd Methods}

Taxonomic Sampling-A total of 46 Pentagramma individuals (Appendix 1) was selected for our phylogenetic analyses, including multiple exemplars of each morphotype (as defined above). Collections were made throughout most of the range of the genus, including Arizona, California, Nevada, Oregon, and Utah in the U. S. A., plus Baja California and Baja California Sur in Mexico. We sampled from areas where a single taxon occurred as well as from areas where more than one taxon occurred.

Spore Counts and Measurements - To aid in the inference of ploidy, spores were examined from 40 of the sampled individuals (the remaining six lacked mature sporangia or were unavailable for study), as well as from 10 type specimens and 11 Pentagramma specimens that were vouchers for chromosome counts (Appendix 1). Using a Leica MZ 7.5 boom dissecting scope and dissecting needles, a single mature (but unopened) sporangium was selected from each specimen and transferred to a small drop of glycerol on a glass microscope slide. Each sporangium was forced open with the needles and its spores released into the glycerol. After removing any debris, a cover slip was carefully placed on the drop to spread the spores. Images of the preparation were then captured using a Canon EOS Rebel XSi digital camera mounted on a Leica MZ 12.5 dissecting scope. From these digital images, normal and malformed spore counts (per sporangium) were obtained, and measurements of a subsample of normal spores (when present) were taken. Individual spore diameters were measured using Image version 1.41 (Abramoff et al. 2004), which was calibrated with a slide micrometer. The mean and standard deviation were calculated for each specimen.

DNA Isolation, Amplification, Cloning, and Sequencing-For each of the 46 individuals selected for phylogenetic analysis, genomic DNA was extracted from silica-dried leaf material using the DNeasy plant mini kit (Qiagen, Valencia, California), following a previously published protocol (Schuettpelz and Pryer 2007). Three loci were separately amplified using the polymerase chain reaction (PCR): the plastid atpA region (comprising a portion of the $\operatorname{atp} F$ gene, the atpF-atp $A$ intergenic spacer, the atp $A$ gene, the $\operatorname{atp} A-\operatorname{trn} R$ intergenic spacer, and the last two base pairs of the $\operatorname{trn} R$ gene; Schuettpelz et al. 2006); the plastid trnG-R region (comprising the last two bases of the first $\operatorname{trn} G$ exon, the $\operatorname{trn} G$ intron, the second $\operatorname{trn} G$ exon, the $\operatorname{trn} G$-trnR intergenic spacer, and the first base of the $\operatorname{trnR}$ gene; Nagalingum et al. 2007); and a segment of the nuclear gapCp (short copy) gene (comprising part of exon 8, introns 8-10 and exons 9-10 in their entirety, and part of exon 11; Schuettpelz et al. 2008). Each $20 \mu 1$ PCR reaction included the following: $1 \times$ PCR buffer (with $1.5 \mathrm{mM} \mathrm{MgCl} 2$ ); $200 \mu \mathrm{M}$ each dNTP; $100 \mu \mathrm{g} / \mathrm{ml}$ BSA; 50 units $/ \mathrm{ml}$ Choice-Taq DNA polymerase (Denville Scientific, Holliston, Massachusetts), $0.5 \mu \mathrm{M}$ each primer (Table 2), and $1 \mu 1$ template DNA eluate. The thermocycling program for the $\operatorname{atp} A$ region entailed an initial denaturation step $\left(95^{\circ} \mathrm{C}\right.$ for $\left.2 \mathrm{~min}\right)$ followed by 35 denaturation, annealing, and elongation cycles $\left(95^{\circ} \mathrm{C}\right.$ for $30 \mathrm{sec}, 45^{\circ} \mathrm{C}$ for $30 \mathrm{sec}$, and $71^{\circ} \mathrm{C}$ for $2 \mathrm{~min}$ ) and a final elongation step $\left(71^{\circ} \mathrm{C}\right.$ for $5 \mathrm{~min}$ ). For both $\operatorname{trnG}-R$ region and gapCp (short copy) gene amplifications, cycle elongations were decreased to $1.5 \mathrm{~min}$; for gap $\mathrm{Cp}$

TABLE 2. Amplification and sequencing primers used in this study of Pentagramma.

\begin{tabular}{|c|c|c|c|c|}
\hline Locus & Primer & Utility (direction) & Sequence $\left(5^{\prime}\right.$ to $\left.3^{\prime}\right)$ & Citation \\
\hline Plastid $\operatorname{atp} A$ region & ESATPF412F & $\begin{array}{l}\text { Amplification/sequencing } \\
\text { (forward) }\end{array}$ & GARCARGTTCGACAGCAAGT & Schuettpelz et al. 2006 \\
\hline Plastid atp $A$ region & ESATPA283F & Sequencing (forward) & GGYAAGATTGCTCAAATACCAG & Schuettpelz et al. 2006 \\
\hline Plastid atpA region & ESATPA557R & Sequencing (reverse) & ATTGTATCTGTAGCTACTGC & Schuettpelz et al. 2006 \\
\hline Plastid atp $A$ region & ESATPA856F & Sequencing (forward) & CGAGAAGCATATCCGGGAGATG & Schuettpelz et al. 2006 \\
\hline Plastid atp $A$ region & ESATPA877R & Sequencing (reverse) & CATCTCCCGGATATGCTTCTCG & Schuettpelz et al. 2006 \\
\hline Plastid atp $A$ region & ESTRNR46F & $\begin{array}{l}\text { Amplification/sequencing } \\
\text { (reverse) }\end{array}$ & GTATAGGTTCRARTCCTATTGGACG & Schuettpelz et al. 2006 \\
\hline Plastid $\operatorname{trn} G-R$ region & TRNG1F & $\begin{array}{l}\text { Amplification/sequencing } \\
\text { (forward) }\end{array}$ & GCGGGTATAGTTTAGTGGTAA & Nagalingum et al. 2007 \\
\hline Plastid trnG-R region & TRNG43F1 & Sequencing (forward) & TGATGCGGGTTCGATTCCCG & Nagalingum et al. 2007 \\
\hline Plastid trnG-R region & TRNG63R & Sequencing (reverse) & GCGGGAATCGAACCCGCATCA & Nagalingum et al. 2007 \\
\hline Plastid trnG-R region & TRNR22R & $\begin{array}{l}\text { Amplification/sequencing } \\
\text { (reverse) }\end{array}$ & CTATCCATTAGACGATGGACG & Nagalingum et al. 2007 \\
\hline $\begin{array}{l}\text { Nuclear gapCp (short copy) } \\
\text { segment }\end{array}$ & ESGAPCP8F1 & $\begin{array}{l}\text { Amplification/sequencing } \\
\text { (forward) }\end{array}$ & ATYCCAAGYTCAACTGGTGCTGC & Schuettpelz et al. 2008 \\
\hline $\begin{array}{l}\text { Nuclear gapCp (short copy) } \\
\text { segment }\end{array}$ & ESGAPCP11R1 & $\begin{array}{l}\text { Amplification/sequencing } \\
\text { (reverse) }\end{array}$ & GTATCCCCAYTCRTTGTCRTACC & Schuettpelz et al. 2008 \\
\hline
\end{tabular}


(short copy) gene amplifications, the annealing temperature was increased to $55^{\circ} \mathrm{C}$. The results of these amplification reactions were visualized on agarose gels.

The PCR products resulting from the gapCp (short copy) region amplifications were successfully ligated into pGEM-T vectors (Promega, Madison, Wisconsin) following the manufacturer's protocol, but using $25 \%$ of the recommended reagent volumes and $0.5 \mu \mathrm{l}$ PCR product. Ligation reactions were incubated overnight at $4^{\circ} \mathrm{C}$. Transformations were performed in $20 \mu \mathrm{l}$ reactions that included: $1 \times \mathrm{KCM}$ buffer $\left(0.1 \mathrm{M} \mathrm{KCl}, 0.03 \mathrm{M} \mathrm{CaCl}_{2}\right.$, and $0.05 \mathrm{M} \mathrm{MgCl}_{2}$ ), $10 \mu \mathrm{l}$ TOP10 cells, and $0.5 \mu \mathrm{l}$ ligation reaction. The cells were incubated together with the buffer and ligation reaction on ice for $30 \mathrm{~min}$, heat-shocked at $42^{\circ} \mathrm{C}$ for $1 \mathrm{~min}$, and then returned to ice, where $180 \mu \mathrm{l}$ of LB broth was added. The transformations were then incubated at $37^{\circ} \mathrm{C}$ for $60 \mathrm{~min}$ (shaking at $200 \mathrm{rpm}$ ) and spread on a selective (ampicillin plus X-gal) LB plate. Plates were incubated at $37^{\circ} \mathrm{C}$ overnight. At least 12 white colonies from each plate were individually picked, re-suspended, and secondarily amplified in $20 \mu \mathrm{l}$ PCR reactions prepared and executed as before, but utilizing the M13 priming sites within the vector and a cycle elongation time of $1 \mathrm{~min}$. The results of these reactions were again visualized on an agarose gel. At least nine $($ mean $=13)$ secondary amplifications corresponding to the "short" copy of the gene (Schuettpelz et al. 2008; a preliminary screen of clones allowed us to target this copy based on size) were selected for clean-up and sequencing.

The primary plastid and secondary nuclear amplifications were cleaned using 5 units of exonuclease I and 1 unit of shrimp alkaline phosphatase (USB Corporation, Cleveland, Ohio), added directly to each reaction tube. Clean-ups were incubated at $37^{\circ} \mathrm{C}$ for $15 \mathrm{~min}$ and then held at $80^{\circ} \mathrm{C}$ for $15 \mathrm{~min}$ to inactivate the enzymes. Sequencing, as well as read assembly and editing, followed established protocols (Schuettpelz and Pryer 2007; Schuettpelz et al. 2008); sequencing primers are provided in Table 2 . The resulting consensus sequences for the plastid atp $A$ and $\operatorname{trn} G-R$ regions were deposited into GenBank (Appendix 1) and were used below. For the nuclear gapCp (short copy) gene, allelic sequences were first extracted from the pools of colony sequences using a relatively simple approach. For each individual, all colony sequences were aligned in MacClade 4.08 (Maddison and Maddison 2005) and a heuristic maximum parsimony analysis was conducted in PAUP* $4.0 \mathrm{~b} 10$ (Swofford 2002), with 100 randomaddition-sequence replicates and TBR branch swapping. If more than one shortest tree was recovered, a strict consensus was computed. Each minimally inclusive clade (singletons were ignored) present in the shortest (or strict consensus) tree was considered to be representative of an allele, and its constituent colony sequences were combined via majority rule consensus. The resulting allelic sequences were deposited in GenBank (Appendix 1), and were used in the analyses below.

Sequence Alignment and Phylogenetic Analysis - The sequences from each region were manually aligned based on similarity (Simmons 2004) in MacClade 4.08 (Maddison and Maddison 2005); no character exclusions were required. The resulting alignments were deposited in TreeBASE (study number 16786). The best-fitting of 88 possible models of sequence evolution was identified for each data set in jModeltest 0.1.1 (Posada 2008; Guindon and Gascuel 2003), using a fixed BIONJ-JC tree and the Akaike information criterion (AIC; Akaike 1974). Best-fitting models, and other alignment statistics, are provided in Table 3).

The three single-region alignments were analyzed independently in PAUP* 4.0b10 (Swofford 2002), using both equally-weighted maximum parsimony and maximum likelihood criteria. All analyses used a heuristic search strategy and TBR branch swapping. Parsimony analyses included 10,000 random addition sequence (RAS) replicates; for likelihood, these were reduced to 2,000. Support was assessed via maximum parsimony and maximum likelihood bootstrapping (Felsenstein 1985) in PAUP*, with 1,000 replicates (10 RAS replicates each) and 200 replicates (two RAS replicates each), respectively. As there was no topological conflict between the single-region plastid trees, a combined plastid data set was also constructed and analyzed (as above). Due to the limited genetic divergence within Pentagramma and the relatively large phylogenetic distance to its nearest relative (Schuettpelz et al. 2007; Schuettpelz and
Pryer 2009), a midpoint rooting approach was employed. Midpoint rooting has been shown to perform well at lower taxonomic levels (Hess and De Moraes Russo 2007) and the alternative, outgroup rooting with a distantly related outgroup, can be problematic (Maddison et al. 1984; Wheeler 1990; Huelsenbeck et al. 2002; Sanderson and Shaffer 2002; Schuettpelz and Hoot 2006).

Taxonomic Delimitation and Conservation Assessment-We follow de Queiroz $(1998,2007)$ in recognizing the existence of a unified species concept that "equates species with separately evolving metapopulation lineages" (de Queiroz 2007, p. 880). Likewise, we consider an independent evolutionary trajectory to be the only necessary property of a species. In looking for evidence of lineage separation, we focused primarily on monophyly (Donoghue 1985; Mishler 1985), diagnosability (Cracraft 1983; Nixon and Wheeler 1990), and reproductive isolation (Mayr 1942; Dobzhansky 1970).

Conservation status was assessed for all recognized taxa according to the IUCN red list categories and criteria (IUCN 2012). The extent of occurrence was calculated for each taxon using the browser-based GeoCAT tool (Bachman et al. 2011) and georeferenced specimen data obtained through the Global Biodiversity Information Facility (www.gbif.org; accessed 24 March 2015).

\section{Results}

Spores - The 61 Pentagramma individuals from which spores were examined each had spore counts consistent with an expectation of 64 spores per sporangium. For most individuals (designated as $\mathrm{N}=$ normal in Appendix 1), the number of normally-formed spores greatly exceeded the number of malformed spores. Only five individuals yielded nearly equal numbers of normally-formed and malformed spores (these are designated as $\mathrm{X}=$ mixed in Appendix 1), and just one individual (Schuettpelz 1291A) was completely lacking normal spores (designated as $\mathrm{L}=$ malformed in Appendix 1). Malformed spores were not measured. For normally-formed spores, overall mean diameters ranged from $30.7 \mu \mathrm{m}$ to $52.4 \mu \mathrm{m}$, with standard deviations typically less than $2 \mu \mathrm{m}$ (Appendix 1). Few large breaks in spore size were observed, but mean diameters from cytogenetically-confirmed diploids, tetraploids, and triploids were non-overlapping (Fig. 1). Known diploid means ranged from $33.8 \mu \mathrm{m}$ to $40.7 \mu \mathrm{m}$ and known tetraploid means from 42.6-45.2. The only cytogenetically-confirmed triploid sporophyte produced an abundance of malformed spores. However, some sporangia from this individual contained well-formed spores that averaged $49.0 \mu \mathrm{m}$; these spores were presumably unreduced (and thus triploid). We took the approach of assuming that individuals were diploid unless there was evidence to suggest they were tetraploid and, in turn, that individuals were tetraploid unless there was evidence to suggest they were triploid (or hexaploid). Thus, we considered all individuals with a mean spore size less than that of the smallest known tetraploid to be diploid, all individuals with a mean spore size less than that of the smallest known triploid but greater than that of the smallest known tetraploid to be tetraploid, and all individuals with a mean spore size greater than that of the largest known triploid to be triploid (or hexaploid). Using these criteria, we inferred 39 of the 49 measured "unknowns"

TAble 3. Datasets used in this study of Pentagramma.

\begin{tabular}{|c|c|c|c|c|}
\hline Dataset & Total characters & Variable characters & Missing data & Best-fitting model \\
\hline Plastid atpA region & 1,828 & 16 & $0.1 \%$ & TPM1uf \\
\hline Plastid trn $G-R$ region & 1,142 & 18 & $0.3 \%$ & HKY \\
\hline Plastid combined & 2,970 & 34 & $0.2 \%$ & TPM1uf \\
\hline Nuclear gapCp (short copy) segment & 776 & 120 & $4.8 \%$ & $\mathrm{TVM}+\mathrm{I}+\mathrm{G}$ \\
\hline
\end{tabular}




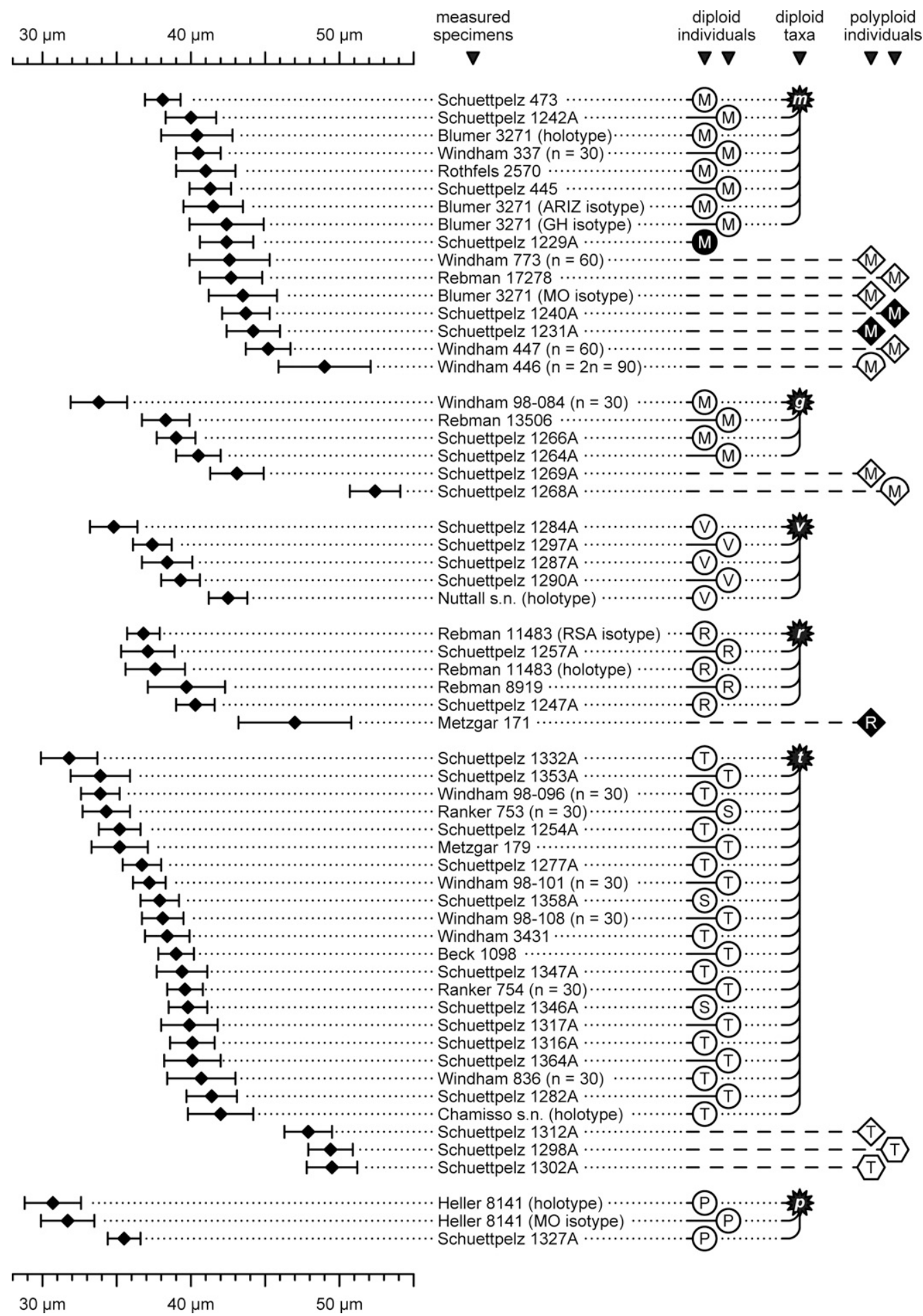

FIG. 1. Spore diameter plots for Pentagramma, including 11 chromosome vouchers, 11 type specimens, and 38 other collections of unknown ploidy. Means (small black diamonds) and standard deviations (flanking bars) are presented. Collection numbers are used to identify each measured specimen, with chromosome number or type status provided in parentheses (as applicable). Plots are grouped by morphotype, based on those exhibited by the six diploid taxa recognized in this study (indicated with white lowercase letters in black starbursts): $m=P$. maxonii; $g=P$. glanduloviscida; $v=P$. viscosa; $r=P$. rebmanii; $t=P$. triangularis; $p=P$. pallida. Specimens inferred (see main text) to be normal diploids are indicated with white circles, diploid hybrids with black circles (only one here), autotetraploids with white diamonds, allotetraploids with black diamonds, autotriploids with white fans, allotriploids with black fans (none in this figure), and autohexaploids with white hexagons. To facilitate a comparison to the most recently published infrageneric classification (Winner and Simpson 2007), individuals are labeled (with uppercase letters) based on morphotypes corresponding to taxa recognized therein: $\mathrm{M}=P$. triangularis subsp. maxonii; $\mathrm{V}=P$. triangularis subsp. viscosa; $\mathrm{R}=P$. triangularis subsp. rebmanii; $\mathrm{T}=P$. triangularis subsp. triangularis; $\mathrm{S}=P$. triangularis subsp. semipallida; $\mathrm{P}=$ P. pallida. For morphotypes corresponding to taxa recognized in the current study, see Appendix 1 . All chromosome counts are from Windham and Yatskievych (2003), except Windham 337 (UT) from Yatskievych et al. (1990) and Windham 446 (DUKE) from unpublished data. 
to be diploid, including all holotypes and all but one isotype. An additional seven individuals were determined to be tetraploid (Appendix 1). The three remaining samples for which spores could be measured had spores of a size suggesting they were from a triploid (unreduced) or hexaploid (reduced); two of these had mostly normal spores that were inferred to be hexaploid and the remaining sample, with a high proportion of malformed spores, was inferred to be triploid. When spores could not be measured, other data were used to assess ploidy (see Discussion section); again, we assumed a lower ploidy level unless there was evidence available with which to infer a higher ploidy level.

Plastid Analyses - The plastid atpA and trnG-R region alignments yielded relatively few variable characters for Pentagramma (Table 3), and analyses of these datasets provided minimal resolution and support (despite a complete lack of homoplasy). Maximum parsimony and maximum likelihood analyses of the combined plastid dataset recovered a single best tree. With midpoint rooting, two large deeply diverging clades were revealed (Fig. 2). This split received strong (100\%) maximum parsimony bootstrap (MPBS) and maximum likelihood bootstrap (MLBS) support. One of the two major clades includes morphotype M, R, and V diploids, as well as six inferred tetraploids and two inferred triploids. The other major clade includes morphotypes $\mathrm{P}, \mathrm{S}$, and $\mathrm{T}$ diploids, plus two inferred hexaploids and one inferred tetraploid. Relationships within these clades are generally unresolved or poorly supported and there are insufficient data to either accept or reject the monophyly of the morphotypes, except for morphotype $\mathrm{T}$, which is strongly supported as paraphyletic (relative to morphotypes $\mathrm{P}$ and $\mathrm{S}$ ).

Nuclear Analyses-We recovered 84 allelic sequences of the nuclear gapCp (short copy) gene from 46 sampled Pentagramma individuals. Nearly three-fourths of these individuals (34 of 46) yielded two allelic sequences and most of the others (10 of 46) just one. Three allelic sequences were obtained from Rebman 14051 and Schuettpelz 1291A; the latter was the lone sample with completely malformed spores (Appendix 1), while the other could not be included in the spore analysis due to a lack of mature sporangia.

The nuclear gapCp (short copy) alignment provided considerably more variable characters than the plastid dataset (Table 3). With some homoplasy present, our analyses of gapCp (short copy) resulted in 6,528 equally most parsimonious

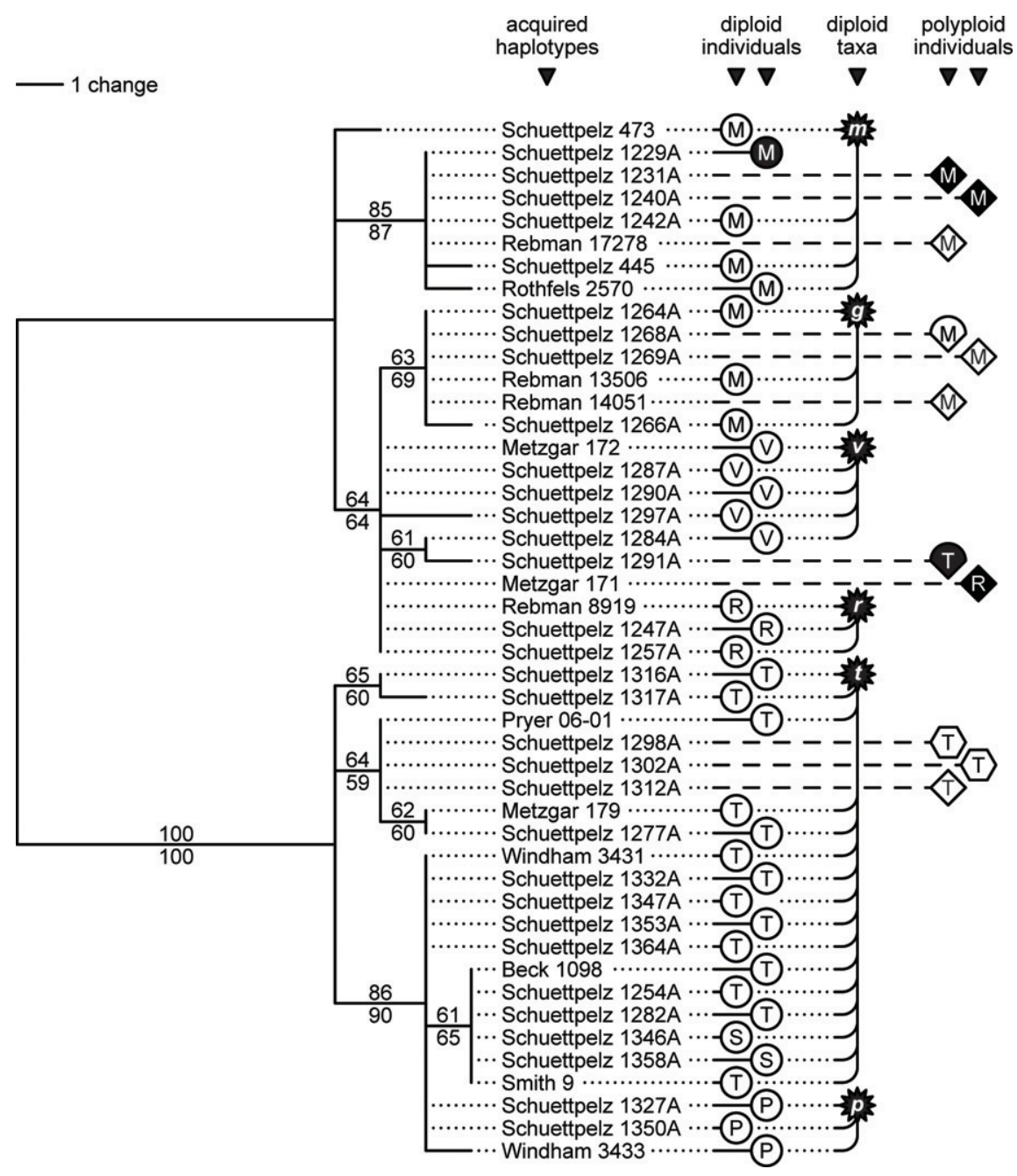

Fig. 2. Most parsimonious tree (rooted at its midpoint) resulting from analysis of the combined plastid haplotypes acquired from 46 Pentagramma individuals. Maximum parsimony and maximum likelihood bootstrap values are provided above and below the branches, respectively. Note that the topology shown is identical to that obtained via maximum likelihood analysis. Collection numbers are used to identify each haplotype. All symbols and labels (for diploid individuals, diploid taxa, and polyploid individuals) correspond to those used in Fig. 1. 


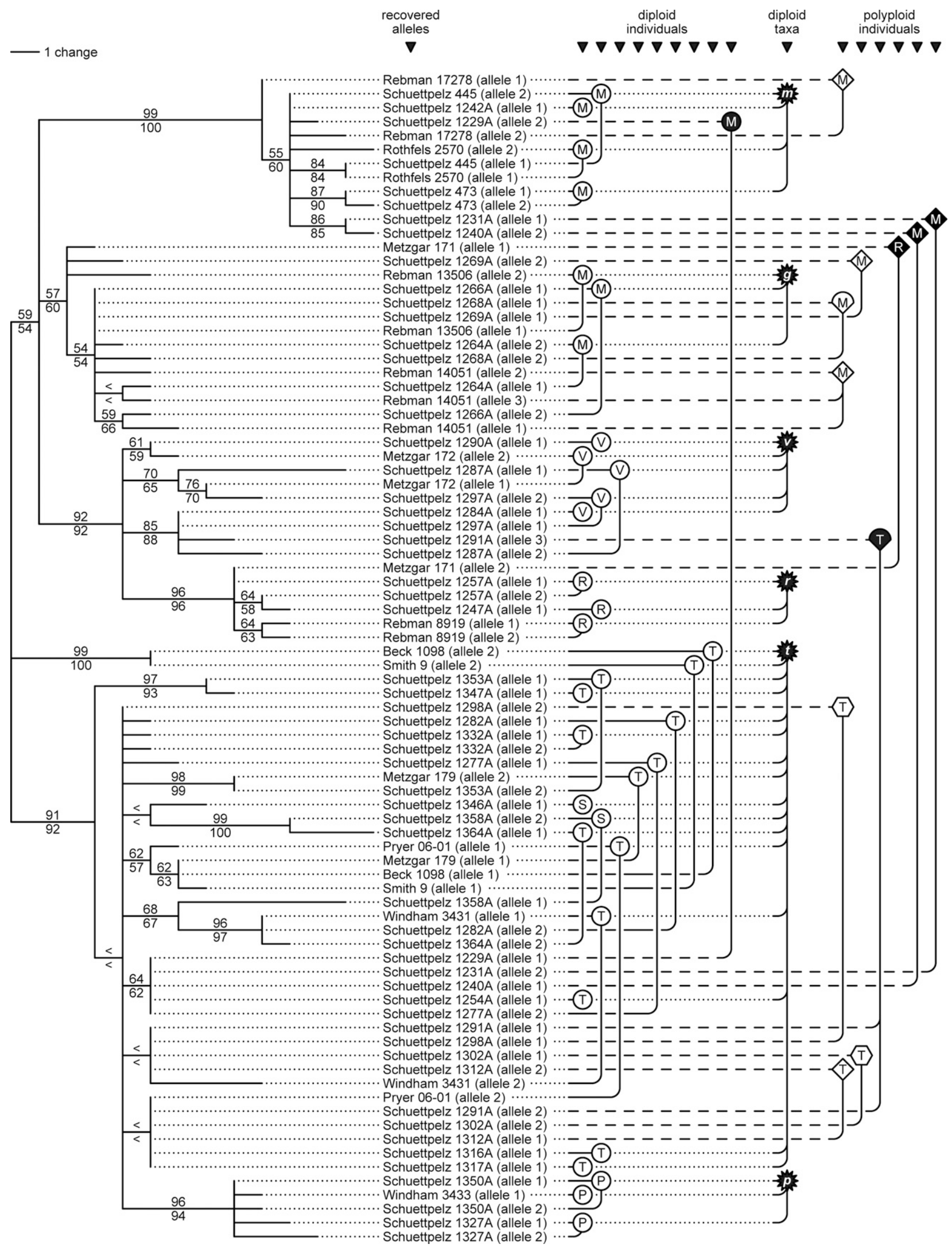

Fig. 3. One of 6,528 most parsimonious trees (rooted at its midpoint) resulting from analysis of the nuclear gap $\mathrm{C} p$ (short copy) alleles recovered from 46 Pentagramma individuals. Maximum parsimony and maximum likelihood bootstrap values are provided above and below the branches, respectively. Note that all nodes with support $\geq 50 \%$ are also present in the strict consensus of the 6,528 equally parsimonious trees, as well as in the strict consensus of the four equally likely trees. The 84 recovered alleles correspond to consensus sequences obtained from 46 sampled individuals (see Materials and Methods) and are identified by collection numbers and arbitrarily assigned allele numbers (in parentheses). All symbols and labels (for diploid individuals, diploid taxa, and polyploid individuals) correspond to those used in Fig. 1; vertical lines are used to join multiple alleles (when present) obtained from each individual. 
and four equally most likely trees. These trees were all remarkably similar and the tree selected at random from the pool of equally parsimonious trees (Fig. 3) is not substantively different from the remaining 6,531 trees. Branch support was again relatively low, but 15 splits did receive both MPBS and MLBS bootstrap scores $\geq 70 \%$.

Alleles recovered from diploid and polyploid individuals are mostly phylogenetically intermixed (Fig. 3). The morphotype R diploid alleles form a well-supported (MPBS = $96 \%$; MLBS $=96 \%$ ) clade and include an allele derived from a polyploid (Metzgar 171 allele 1). A single polyploid allele (Schuettpelz 1291A allele 3) is also associated with the morphotype $\mathrm{V}$ diploids; this group is not resolved as monophyletic, but the three morphotype $\mathrm{V}$ clades are interconnected by sampled diploid individuals (Fig. 3). Morphotype M diploids form two distinct clades, each with associated polyploid alleles. One of these clades is robustly supported (MPBS = $99 \%$; MLBS $=100 \%)$; the other is not $($ MPBS $=57 \%$; MLBS $=$ $60 \%$ ). Nonetheless, these clades appear to be distinct. Alleles recovered from morphotype $\mathrm{T}$ diploids are intermixed with polyploid alleles, and they are also strongly supported as paraphyletic to morphotypes $\mathrm{P}$ and $\mathrm{S}$. As with morphotype V, the distinct morphotype $\mathrm{T}$ groupings are linked by sampled diploid individuals (Fig. 3). Morphotype P alleles form a wellsupported clade $($ MPBS $=96 \%$; MLBS $=94 \%$ ), with no affiliated polyploid alleles. Alleles from morphotype $S$ are not resolved as monophyletic.

There is little evidence for homoploid hybridization among the diploid morphotypes; Schuettpelz $1229 \mathrm{~A}$ is the only inferred diploid to have alleles associated with two different morphotypes ( $\mathrm{M}$ and $\mathrm{T})$. However, polyploids appear to have been formed readily both within and among the diploid morphotypes. The alleles recovered from polyploids Rebman 14051, Rebman 17278, Schuettpelz 1268A, and Schuettpelz $1269 A$ all fall within a morphotype M clade. Similarly, polyploids Schuettpelz 1298A, Schuettpelz 1302A, and Schuettpelz $1312 A$ all have alleles that are associated exclusively with alleles from morphotype $\mathrm{T}$ diploids. Polyploids Schuettpelz 1231A and Schuettpelz 1240A appear to have resulted from crosses between morphotype $\mathrm{M}$ and morphotype T individuals. Likewise, polyploid Metzgar 171 appears to have resulted from a cross between morphotypes $\mathrm{M}$ and $\mathrm{R}$, and polyploid Schuettpelz 1291A is a cross between morphotypes $\mathrm{V}$ and $\mathrm{T}$. Morphotypes $\mathrm{S}$ and $\mathrm{P}$ do not appear to have been involved in any polyploid formation based on the current sampling.

\section{Discussion}

Ploidy Level Assessment-Spore size has been shown to be a reasonably reliable indicator of ploidy level in ferns (Barrington et al. 1986; Grusz et al. 2009; Beck et al. 2010; but see Dyer et al. 2013). Spore measurements from 11 cytogenetically analyzed individuals (Windham and Yatskievych 2003; Yatskievych et al. 1990; Windham, unpublished data) demonstrate the usefulness of this approach within Pentagramma (Fig. 1). Thus, based on spore size, we were able to infer the ploidy of 39 individuals sampled for our genetic analyses, plus 10 type specimens of Pentagramma (Fig. 1). Thirty-nine of these 49 measured "unknowns" were inferred to be diploid, including all holotypes and all but one isotype (Fig. 1; Appendix 1); ten were determined to be polyploid (Appendix 1). The number of alleles obtained per individual was consistent with these determinations; about $25 \%$ of inferred diploids had a single nuclear gap C $p$ allele and no more than two alleles were recovered from any of the 39 inferred diploids (Appendix 1). Although all samples inferred to be polyploid, based on spore measurements, were also limited to two alleles, none of these had just one allele.

A lack of mature sporangia for six individuals and the absence of normal spores in another necessitated the use of complimentary data to assist in inferring ploidy. For one individual (Metzgar 172), we used an existing chromosome count taken previously from the same population (Windham and Yatskievych 2003). For each of the six others, we based our conclusion primarily on the number of alleles obtained and their phylogenetic position; here again, we assumed these individuals to be diploid unless there was evidence to the contrary. The two morphotype $\mathrm{P}$ individuals lacking spores (Schuettpelz 1350A and Windham 3433) were inferred to be diploid, as their alleles (two and one obtained, respectively; Fig. 3) were closely associated with those from the morphotype P individual (Schuettpelz 1327A) for which spores could be measured (morphotype $\mathrm{P}$ is only known only as a diploid; Alt and Grant 1960). Smith 9 was inferred to be a diploid because it possessed alleles that were nearly identical to those from Beck 1098 (Fig. 3), which had spores well within the diploid range (Fig. 1). Pryer 06-01 was treated as a diploid because there was no data to suggest otherwise. The remaining two specimens (Rebman 14051 and Schuettpelz $1291 A$ ) each had three alleles, suggesting they were polyploid.

It is certainly possible that some of our assessments of ploidy noted above are incorrect, especially in cases where spores were not available for study. Nonetheless, we are quite confident that any effect of mistaken inference on our overall taxonomic conclusions would be minimal.

Diploid Taxa-The phylogenies we recovered for Pentagramma (Figs. 2, 3) are neither fully resolved nor especially well supported. Nonetheless, they are remarkably consistent with morphology and the few deviations from the most recent taxonomic treatment (Winner and Simpson 2007) can be logically explained. Here, we first discuss our findings at the diploid level, ignoring polyploid alleles and haplotypes in our assessments of diploid exclusivity and monophyly. Polyploid origins are discussed only after we have established a diploid framework.

Morphotype R has only recently been described, as Pentagramma triangularis subsp. rebmanii (Winner and Simpson 2007). Nonetheless, alleles from sampled diploids of morphotype $\mathrm{R}$ do form a well-supported clade in our nuclear phylogeny (Fig. 3). Although the plastid results are inconclusive, with morphotype $\mathrm{R}$ sharing a haplotype with some morphotype $\mathrm{V}$ individuals (Fig. 2), we see no reason to dismiss this taxon. Morphologically, it is distinct from its closest relative, morphotype $\mathrm{V}$, exhibiting adaxial leaf surfaces covered with sparse farina as opposed to a viscid exudate (Winner and Simpson 2007).

Morphotype $\mathrm{V}$ was found to have two unique plastid haplotypes and another that is shared with morphotype $\mathrm{R}$ (Fig. 2). Nuclear allelic sequences from morphotype V diploids were never shared with morphotype $\mathrm{R}$, but the three clades containing these alleles were resolved in a polytomy with the singular morphotype R clade (Fig. 3). All the same, when two alleles were recovered from a given morphotype $\mathrm{V}$ individual, they always originated from different morphotype $\mathrm{V}$ clades, suggesting substantial genetic cohesion despite 
an apparent lack of monophyly. We feel this warrants the continued taxonomic recognition of this entity, characterized by its uniquely dissected leaves with viscid adaxial surfaces (Alt and Grant 1960; Yatskievych et al. 1990).

Sequences from morphotype $\mathrm{M}$ diploids are mostly confined to two clades of roughly equal size in our nuclear phylogeny (Fig. 3). One of these clades, containing nearly all of the alleles from our sampled diploid Arizona individuals (the sole exception, allele 1 of Schuettpelz 1229A, is discussed below), is well supported as monophyletic (MPBS $=99 \%$; MLBS $=100 \%$ ). The other clade, including all of the alleles from our diploid California individuals (all sampled from the California floristic province), is not well supported $(\mathrm{MPBS}=57 \%$; MLBS $=60 \%)$, but is present in the strict consensus (of all 6,528 shortest trees; not shown). The plastid results are similar, although one haplotype from Arizona (Schuettpelz 473) is isolated from the other Arizona collections that are resolved together in a clade (MPBS $=85 \%$; MLBS $=87 \%$; Fig. 2). A single nuclear allele from one morphotype $\mathrm{M}$ individual collected in Arizona (allele 1 from Schuettpelz 1229A; Fig. 3) did not conform to the overall pattern described above. This allele was not resolved with other morphotype $\mathrm{M}$ alleles from Arizona, but rather with those of morphotype $\mathrm{T}$, suggesting a hybrid origin for this individual (the only evidence of hybridization we uncovered that was not associated with polyploidy).

Excluding the inferred $\mathrm{M} \times \mathrm{T}$ hybrid mentioned above, there is nothing contradicting the monophyly of morphotype $\mathrm{M}$ and it would be phylogenetically acceptable to continue treating this morphotype as a single taxon. However, there is also nothing to suggest that morphotype $\mathrm{M}$ as a whole is monophyletic. Considering the geographic exclusivity between the two clades, and the lack of any evidence of gene flow between them, subdivision seems more reasonable. Morphology, as it turns out, supports this decision.

The type M morphotype was previously recognized by the ubiquitous presence of glands on the adaxial leaf surfaces. However, upon closer inspection, it is clear that gland morphology actually differs between the two morphotype $M$ clades. Our sampled specimens from Arizona (and other plants from Arizona, Baja California Sur, New Mexico, Sonora, and the Sonoran Desert in California and Baja California) have inconspicuously stalked glands frequently bearing small protuberances, whereas those from the California floristic province in California (and other plants from the California floristic province in California and Baja California) have conspicuously stalked glands lacking such protuberances (Fig. 4E). Additionally, specimens from the California floristic province are, like morphotype $\mathrm{V}$, adaxially viscid, a condition never observed in specimens from the other areas. Gross leaf morphology also varies between the clades, with plants from the California floristic province having leaves that are essentially pinnate (somewhat longer than wide with basal pinnae each smaller in size than the remainder of the leaf) and those from the other areas having leaves that are essentially ternate (about as long as wide with basal pinnae each about equivalent in size to the remainder of the leaf). Based on the sum of this evidence, we favor recognizing the plants from the California floristic province as a new taxon, distinct from the other plants that remain, themselves, worthy of taxonomic recognition. Our taxonomic delimitation closely follows the geographic divisions proposed by Takhtajan (1986), with one taxon restricted to his Californian Province and the other to his Sonoran Province.
Morphotype P has long been seen as the most distinctive within Pentagramma, and it is generally treated as a separate species, P. pallida (Yatskievych and Windham 1993). This taxon is readily distinguished from other elements in the genus based on its densely farinose adaxial leaf surfaces and farinose petioles. In our nuclear analyses, we find alleles from morphotype $\mathrm{P}$ diploids to be unique and well supported as monophyletic (MPBS $=96 \%$; MLBS $=94 \%$; Fig. 3). However, this clade is not sister to the remainder of the genus, as would be expected based on earlier classifications; it is, instead, part of a large polytomy encompassing all individuals of morphotype $S$ and most morphotype T samples (Fig. 3). In our plastid analyses, morphotype P haplotypes are similarly resolved in a polytomy with morphotype $\mathrm{T}$ and $S$ haplotypes (Fig. 2). Although its relationship to morphotype $\mathrm{T}$ remains unresolved, it seems reasonable to maintain morphotype $\mathrm{P}$ as taxonomically distinct due to its unique morphology and clear monophyly in our nuclear analyses.

Morphotype $S$ shares its only recovered plastid haplotype with morphotype T (Fig. 2), and although its nuclear alleles are unique, they do not form a clade (Fig. 3). One nuclear allele of morphotype S (Schuettpelz 1358A allele 2) is strongly supported as sister to a morphotype $\mathrm{T}$ allele (Schuettpelz $1364 A$ allele 1 ) to the exclusion of the other morphotype $S$ sequences. The morphological distinction between morphotypes $\mathrm{S}$ and $\mathrm{T}$ is relatively slight, as they differ only in farina color. Morphotype $\mathrm{S}$ has abaxial leaf surfaces that are covered in white farina, whereas morphotype $\mathrm{T}$ has abaxial leaf surfaces covered in yellow farina. Both are adaxially glabrous and the narrow distribution of morphotype $S$ is contained within that of morphotype T (Alt and Grant 1960; Yatskievych and Windham 1993). Therefore, we favor the approach of Mickel and Smith (2004), incorporating morphotype $S$ into an expanded morphotype $\mathrm{T}$ (characterized simply by adaxially glabrous leaf surfaces).

Morphotype T, although easily segregated by its adaxially glabrous and abaxially yellow farinose leaf surfaces is the most complex of the previously recognized taxa. It encompasses several flavonoid chemotypes (Smith et al. 1971; Smith 1980; Wollenweber et al. 1985) and considerable morphological variation (Alt and Grant 1960; Yatskievych et al. 1990). This morphotype is also, by far, the most widely distributed (Alt and Grant 1960; Yatskievych and Windham 1993). It is not surprising then that it has considerable genetic diversity. In our plastid analysis, the six haplotypes we recovered were not resolved as monophyletic (Fig. 2); two were placed in a well-supported (MPBS $=86 \%$; MLBS = $90 \%$ ) clade with identical morphotype P and S sequences. As noted above, nuclear alleles from morphotype $\mathrm{T}$ were also paraphyletic to those from morphotypes P and S (Fig. 3). There are no shared alleles, but one morphotype $\mathrm{T}$ allele is strongly supported as sister to an S allele (MPBS $=99 \%$; MLBS $=100 \%$ ). Additionally, two alleles associated with morphotype T (Beck 1098 allele 2 and Smith 9 allele 2, both from outlying populations) are strongly supported (MPBS = $91 \%$; MLBS $=92 \%$ ) as distinct from the remainder of the $\mathrm{T}$, $\mathrm{S}$, and $\mathrm{P}$ clade. There was no additional support to preclude the monophyly of morphotype $\mathrm{T}$ diploid alleles. Considering the morphological and chemical variation detected within morphotype T by previous authors (Alt and Grant 1960; Smith et al. 1971; Smith 1980), it seems likely that several distinct lineages are present. However, because there is no clear link between these data and our phylogenetic results, 


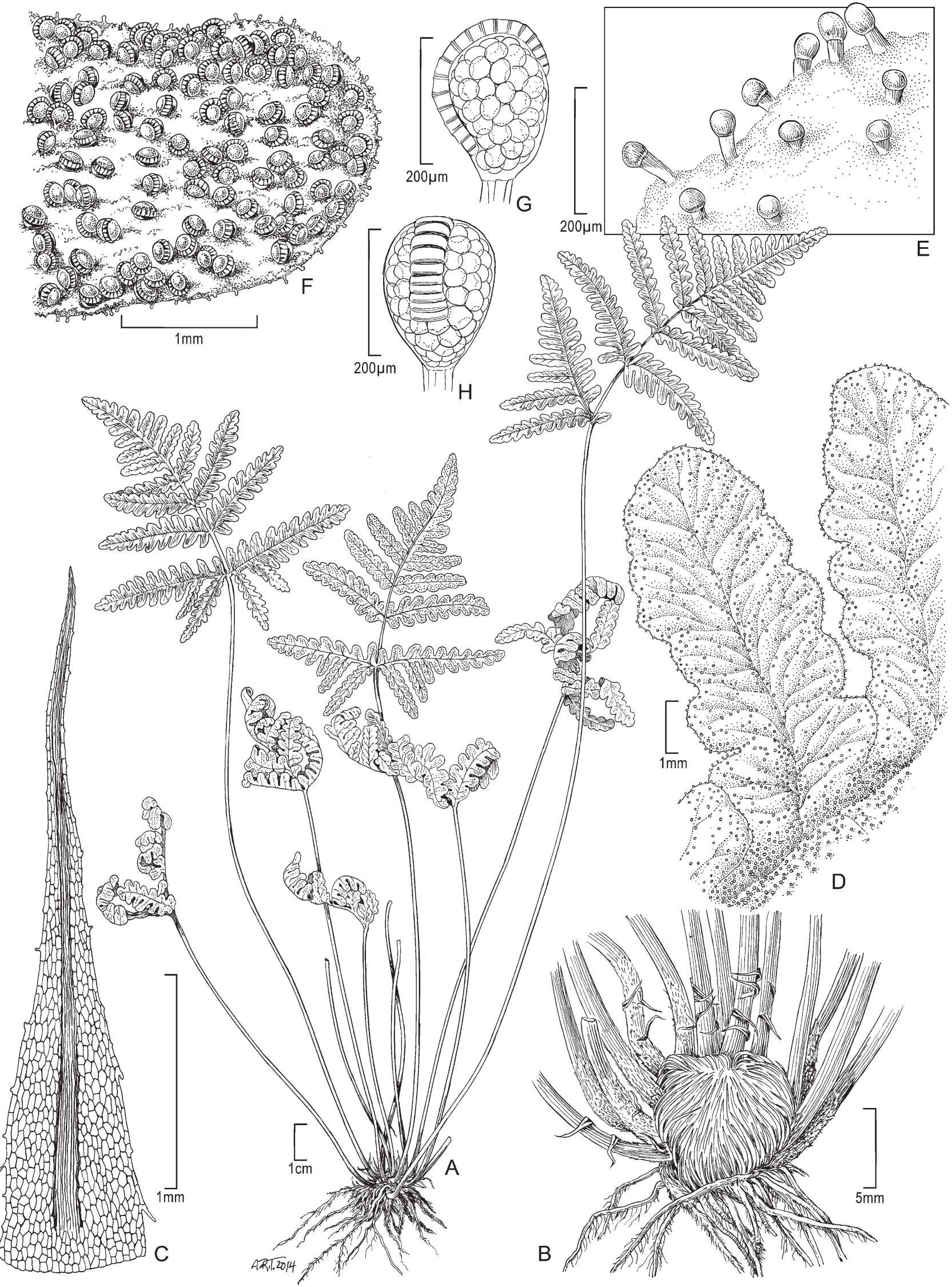

Fig. 4. Pentagramma glanduloviscida. A. Habit. B. Detail of rhizome and petiole bases. C. Scale from base of petiole. D. Adaxial surface of lamina. E. Detail of glands on adaxial surface of lamina. F. Abaxial surface of lamina with farina and sporangia. G. Sporangium (lateral view). H. Sporangium (face view). All drawings based on Schuettpelz 1264A (DUKE, holotype), except B and C from Schuettpelz 1266A (DUKE), and D from field photograph of plant in type population. 
we feel that any splitting of this group would be premature. Therefore, we favor the approach of treating the whole of morphotype $\mathrm{T}$, as well as morphotype $\mathrm{S}$, as a single taxon.

Diploid Species - In the past, the taxa now assigned to Pentagramma have been seen as comprising three (Alt and Grant 1960), two (Smith 1980; Yatskievych et al. 1990; Winner and Simpson 2007), or even one (Weatherby 1920) species. From the beginning, the degree of divergence among the known morphotypes was questioned (Weatherby 1920) and, as additional segregates were identified, they were almost always treated at an infraspecific level. Hybridization was thought to be ubiquitous, and the morphological discontinuities among taxa slight. With our newly obtained plastid and nuclear data, we are better able to assess the genetic structure within Pentagramma and look for gene flow among its segregates. In the previous section, we described evidence supporting the division of Pentagramma into six diploid taxa (indicated by brackets $m, g, v, r, t$, and $p$ in Figs. 2 and 3). Here, we discuss the rank at which these taxa should be recognized.

Based on our results, it is clear that the common practice (Smith 1980; Yatskievych et al. 1990; Winner and Simpson 2007) of treating taxon $p$ as a distinct species ( $P$. pallida), while recognizing the other taxa as varieties or subspecies (of $P$. triangularis), is untenable. Taxon $p$ is no more, and may well be less, phylogenetically divergent than are the remaining entities (Figs. 2,3). If two species were to be recognized based on our plastid tree, they would have to parallel the deep split separating taxa $m, g, v$, and $r$ from taxa $t$ and p. However, morphological support for this split is lacking, and the nuclear results (Fig. 3) are not compatible with the plastid data (Fig. 2). As there are no other deep and wellsupported splits emerging from our phylogenetic analyses, the options for revising the classification of Pentagramma are somewhat limited.

One option would be to recognize $P$. triangularis without infraspecific division. We do not favor this course of action because it fails to account for the morphological variability that has long been recognized within the group (Table 1), as well as the genetic variability we have uncovered here. Another approach would be to treat all six diploid taxa as subspecies of $P$. triangularis (we consider treatment as varieties to be effectively equivalent). With all relevant holotypes here inferred to be diploid (Fig. 1), this would simply involve synonymizing $P$. triangularis subsp. semipallida under $P$. triangularis subsp. triangularis and describing a new subspecies to accommodate the splitting of P. triangularis subsp. maxonii discussed above. A third option would be to accept all six taxa as distinct species within the genus Pentagramma. Although this represents a substantial departure from previous classifications, it would only require the description of a single new taxon (as above) and three new combinations.

Based on the available evidence, we ultimately find the six taxa identified above to be evolving independently and we therefore feel they are worthy of recognition at the species, rather than subspecies, level (following the unified species concept of de Queiroz 1998, 2007). The phylogenies we recovered for Pentagramma, although mostly lacking strong support, are remarkably consistent with morphology. The taxa we recognize are therefore easily diagnosed (see key to taxa below). There were no shared nuclear alleles, even in mixed populations, which is consistent with the absence of gene flow. In addition, we found almost no evidence of inter- breeding among the six taxa at the diploid level, encountering only one putative homoploid hybrid (Schuettpelz 1229A). Four of the six taxa were resolved as monophyletic in our nuclear trees, three with strong support (Fig. 3); only taxon $t$ is resolved as paraphyletic with strong support, but even here there are connections (within individuals; see Beck 1098, Smith 9, Schuettpelz 1353A, and Schuettpelz 1347A; Fig. 3) between the outlying clades and the core of the taxon.

In summary, each of the six taxa we uncovered (Figs. 2, 3) appears to be on a separate evolutionary trajectory. For this reason, we feel that recognition at the species level is warranted and we here identify six species within Pentagramma (see Taxonomic Treatment below): P. glanduloviscida, P. maxonii, $P$. pallida, $P$. rebmanii, $P$. triangularis, and $P$. viscosa. Of course, more intensive and extensive research will be required to test this taxonomic hypothesis, but we feel that this approach to classification is the best representation based on the totality of evidence currently available.

Polyploids - Of the 46 Pentagramma individuals sampled for phylogenetic analysis, 11 were inferred to be polyploid, based on spore measurements or other data (Appendix 1). The putative polyploids included triploids, tetraploids, and hexaploids; both autopolyploids and allopolyploids were encountered. The polyploid individuals we examined uniformly resemble one of their parents (differing only in spore size).

Glandular polyploids associated with morphotype $M$ have been previously reported (Windham and Yatskievych 2003), and it was generally assumed that they were derived exclusively from glandular diploids. Here, we find evidence of autopolyploid formation within both species exhibiting a glandular morphotype (P. maxonii and P. glanduloviscida). Rebman 17278, from the Sonoran Desert in Baja California, is superficially identical to and phylogenetically affiliated with $P$. maxonii (taxon $m$ ), yet has spores in the tetraploid size range (Fig. 1). Similarly, Schuettpelz 1268A, Schuettpelz 1269A, and Rebman 14051 exhibit morphology consistent with their placement within P. glanduloviscida (taxon $g$ ), but spore size (Schuettpelz 1268A and Schuettpelz 1269A) or allele number (three alleles for Rebman 14051) suggests a higher ploidy level. Schuettpelz 1268A was observed to have exceedingly large normal spores (Fig. 1), but also many malformed spores (Appendix 1); we interpreted this individual as triploid. Schuettpelz $1269 \mathrm{~A}$ had mostly normal spores in the tetraploid range. Without evidence to suggest otherwise, we assumed Rebman 14051 was a tetraploid.

Autopolyploids were also encountered within $P$. triangularis (taxon $t$ ). Schuettpelz 1298A, 1302A, and 1312A all have large spores (Fig. 1), but are otherwise morphologically indistinguishable from $P$. triangularis. Based on spore size (Fig. 1) and form (nearly all were normal), we identified Schuettpelz 1298A and $1302 A$ as potential hexaploids. With somewhat smaller spores, Schuettpelz 1312A is inferred to be a tetraploid. Earlier studies indicated that polyploid formation within $P$. triangularis may be common (Alt and Grant 1960; Smith et al. 1971) and additional work is certainly needed.

With the exception of $P$. pallida, all diploid species have been involved in the formation of allopolyploids. Tetraploids (based on spore size; Fig. 1) Schuettpelz $1231 \mathrm{~A}$ and $1240 \mathrm{~A}$ were both collected within the range of $P$. maxonii (taxon $m$ ) and have the glandular adaxial leaf surfaces characteristic of this diploid. However, it is clear from the nuclear data that $P$. triangularis (taxon $t$ ) was also involved in their formation (Fig. 3). Based on our plastid data (Fig. 2) and our understanding 
of plastid inheritance in cheilanthoid ferns (Gastony and Yatskievych 1992), we can identify P. maxonii as the maternal parent and $P$. triangularis as paternal contributor. These two diploid parents have different farina chemistry (Smith 1980; Wollenweber and Dietz 1980; Wollenweber and Smith 1981) and the poorly developed farina in the allotetraploids may reflect incompatibility between the competing chemical pathways as reported in other Pentagramma hybrids (Smith et al. 1971; Smith 1980).

Pentagramma triangularis was also implicated in the formation of a second allopolyploid, with $P$. viscosa. Two alleles from Schuettpelz $1291 A$ were associated with $P$. triangularis (taxon $t$ ), but the third with $P$. viscosa (taxon $v$ ). Based on the presence of malformed spores (we did not find a single normal spore) and the number of unique alleles recovered, it seems reasonable to conclude that this specimen is an allotriploid. From the plastid data and the distribution of nuclear alleles obtained from this individual, we can infer that diploid $P$. viscosa was the maternal parent whereas an autotetraploid formed from within $P$. triangularis was the source of the paternal contribution. As would be expected, this allotriploid most resembled the paternal parent, $P$. triangularis, which contributed two of the three sets of chromosomes.

The nuclear gapC $p$ data also revealed the existence of a third allopolyploid, which incorporates genomes from $P$. glanduloviscida (taxon $g$ ) and $P$. rebmanii (taxon $r$ ). The only sampled representative of this allopolyploid (Metzgar 171) appears to be tetraploid based on spore size (Fig. 1). The plastid results (Fig. 2) indicate that P. rebmanii, which the polyploid resembles, was the maternal parent.
Our spore studies and phylogenetic analyses provide important insights into the evolution of Pentagramma at both the diploid and polyploid levels. We have found evidence for the existence of six diploid taxa within the genus, each of which exhibits a distinctive morphology and a unique suite of nuclear alleles. Although not always demonstrably monophyletic, these taxa appear to be reproductively isolated and independently evolving. For these reasons, we treat them all as distinct species (see Taxonomic Treatment below). Interactions among these species are, based on our sample, almost entirely limited to the formation of polyploids. Such polyploids have arisen both within and between the diploid entities with considerable frequency and we are certain that additional research will lead to the discovery of additional polyploids not sampled here. As such, we have not attempted to address polyploid taxonomy in the current paper. Ferns are well known for their high levels of polyploidy (e.g. Walker 1966, 1984; Manton and Vida 1968; Löve et al. 1977) and frequently limited suite of morphological characteristics. We believe that our approach, although here restricted in sample size and sequencing breadth, represents a workable solution for understanding the evolutionary history of this important group of plants.

\section{TAxonomic Treatment}

Pentagramma Yatsk., Windham \& E. Wollenw., Amer. Fern J. 80: 13. 1990.-TYPE: Pentagramma triangularis (Kaulf.) Yatsk., Windham \& E. Wollenw.

\section{Key to the Diploid Species of Pentagramma}

1. Adaxial leaf surfaces glabrous, rarely with sparse yellow farina; abaxial leaf surfaces yellow farinose, rarely white farinose ........ P. triangularis

1. Adaxial leaf surfaces viscid, glandular, white farinose, or some combination of these; abaxial leaf surfaces white farinose ............. 2

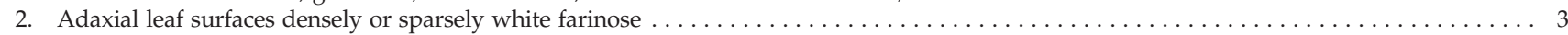

3. Adaxial leaf surfaces densely white farinose, generally obscuring lamina; petioles white farinose; plants of the

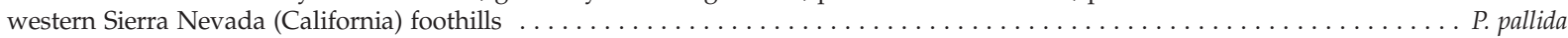

3. Adaxial leaf surfaces sparsely white farinose, not obscuring lamina; petioles glabrous; plants of San Diego County

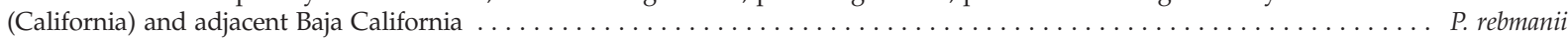

2. Adaxial leaf surfaces viscid, glandular, or both, occasionally appearing yellow farinose $\ldots \ldots \ldots \ldots$

4. Distal pinnae and proximal basiscopic lobes of basal pinnae entire or irregularly pinnatifid; adaxial leaf surfaces

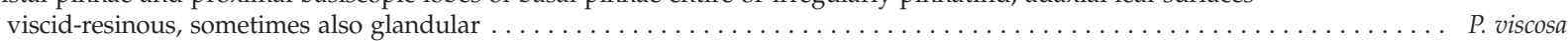

4. Distal pinnae and proximal basiscopic lobes of basal pinnae regularly pinnatifid or more divided; adaxial leaf surfaces

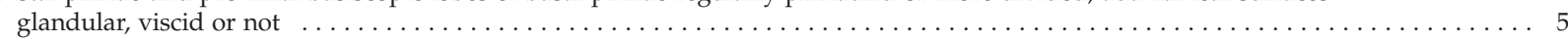

5. Adaxial leaf surfaces not viscid but with inconspicuously stalked glands frequently bearing small protuberances; leaves about as long as wide, essentially ternate (basal pinnae each about equivalent in size to remainder of leaf); plants of Arizona, Baja California Sur, New Mexico, Sonora, and the Sonoran Desert in California and

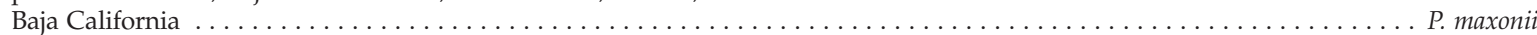

5. Adaxial leaf surfaces viscid and with conspicuously stalked glands lacking small protuberances; leaves somewhat longer than wide, essentially pinnate (basal pinnae each smaller in size than remainder of leaf); plants of the Californian floristic province in California and Baja California

Pentagramma glanduloviscida Schuettp. \& Windham, sp. nov.-TYPE: U. S. A.: California, San Diego County: $4 \mathrm{~km}$ S of Engineer Springs: along Marron Valley Road, 32.59292, -116.76492, elevation 351 m, 13 May 2008, Schuettpelz 1264A (holotype: DUKE! [accession 405736]).

Differs from Pentagramma maxonii (Weath.) Schuettp. \& Windham in having viscid adaxial leaf surfaces with conspicuously stalked glands lacking small protuberances and in having leaves that are somewhat longer than wide. Figure 4.

Distribution-Known only from the California floristic province in California (apparently restricted to San Diego County) and Baja California.
Conservation Assessment-This species has a restricted distribution (extent of occurrence estimated to be about $6,000 \mathrm{~km}^{2}$ ), but many populations are situated in protected areas. It is assigned a preliminary conservation status of near threatened (NT).

Notes-The holotype is inferred to be diploid based on spore measurements; a morphologically similar specimen (Windham 98-084) is a known diploid (Fig. 1). As noted in the main text, polyploids resembling this species but with larger average spore sizes have been found; these are listed separately below, following the inferred or known diploid specimens.

Additional Inferred or Known Diploid SpecimensU. S. A. California: San Diego County: $5 \mathrm{~km}$ SE of Jamul: off 
of CA-94: hill SE of Jamul Creek (Rancho Jamul Ecological Reserve), 32.67782, -116.86026, elevation 311 m, 13 May 2008, Schuettpelz 1266A (DUKE). California: San Diego County: Barrett Lake: on the northwest-facing slope around the immediate area on the east side of the dam, 32.6783, -116.6703, elevation 492 m, 8 May 2007, Rebman 13506 (SD). California: San Diego County: SW of Rancho Bernardo along Black Mountain Road in La Jolla Valley, 33.0023, -117.1215, elevation 115 m, 30 Mar 1998, Windham 98-084 (UT [known diploid]).

Inferred Polyploid Specimens Resembling this SpeciesU. S. A. California: San Diego County: Del Dios Highlands County Preserve: SW of Escondido, just west of S-6 (Del Dios Highway) and NW of Lake Hodges, 33.085, -117.1325, elevation 357 m, 17 Feb 2008, Rebman 14051 (SD). California: San Diego County: Spring Valley: Dictionary Hill, 32.72544, -116.98322, elevation 192 m, 13 May 2008, Schuettpelz 1268A (DUKE). California: San Diego County: Spring Valley: Dictionary Hill, 32.72544, -116.98322, elevation 192 m, 13 May 2008, Schuettpelz 1269A (DUKE).

Pentagramma maxonii (Weath.) Schuettp. \& Windham, comb. et stat. nov. Pityrogramma triangularis (Kaulf.) Maxon var. maxonii Weath., Rhodora 22: 119. 1920. Pentagramma triangularis (Kaulf.) Yatsk., Windham \& E. Wollenw. subsp. maxonii (Weath.) Yatsk., Windham \& E. Wollenw., Amer. Fern J. 80: 16. 1990.—TYPE: U. S. A.: Arizona, Pima County: Rincon Mountains: head of Rincon Valley, elevation 1,067 m, 27 July 1909, Blumer 3271 (holotype: US! [accession 592740]; isotypes: ARIZ!, DS [ploidy level not assessed], GH!, MO! [inferred polyploid]).

Distribution-Extending from southwestern New Mexico across Arizona to Sonora, Baja California Sur, and the Sonoran Desert in California and Baja California.

Conservation Assessment-This species has a broad distribution (extent of occurrence estimated to be about $400,000 \mathrm{~km}^{2}$ ), with some populations situated protected areas. It is assessed to be of least concern (LC).

Notes-Spores were measured from four of the five type specimens (we did not examine the DS isotype). The holotype (US) and the ARIZ and GH isotypes were inferred to be diploid (Fig. 1), with the spores of the holotype being slightly smaller than those of Windham 337, a known diploid. The MO isotype, along with several other collections, had spore sizes between those of two known tetraploids (Windham 447 and Windham 773) and were thus inferred to be polyploid. These polyploid specimens, which were otherwise similar in morphology to P. maxonii, are listed separately below, following the inferred or known diploids. A single hybrid specimen, also resembling $P$. maxonii, is likewise listed separately.

Additional Inferred or Known Diploid Specimens-U. S. A. Arizona: Cochise County: Fort Huachuca: tributary of Garden Canyon, 31.46889, -110.34667, elevation 1,725 m, 18 Mar 2005, Schuettpelz 473 (DUKE). Arizona: Cochise County: Huachuca Mountains: small tributary of Garden Canyon, 31.469, -110.3466, elevation 1,735 m, 14 Nov 1981, Windham 337 (UT [known diploid]). Arizona: Gila County: Tonto National Forest: Barnhardt Canyon, 34.09167, -111.43583, elevation 1,330 m, 15 Mar 2005, Schuettpelz 445 (DUKE). Arizona: Pima County: $24 \mathrm{~km} \mathrm{~N}$ of border with Mexico, 7 km E of AZ-85: Alamo Canyon (Organ Pipe Cactus National Monument), 32.06489, -112.70966, elevation 763 m, 11 May
2008, Schuettpelz 1242A (DUKE). Arizona: Yavapai County: $9.25 \mathrm{~km} \mathrm{~N}$ of Congress (as the crow flies): S side of Date Creek Road, 34.2438, -112.88153, elevation 1,021 m, 17 May 2008, Rothfels 2570 (DUKE).

Inferred or Known Polyploid Specimens Resembling this

Species-MEXICO. Baja California: Ensenada: Sierra La Libertad: NE of the abandoned Rancho El Paraiso: along the riparian area of a small palm canyon off (E) of Arroyo El Paraiso, 28.5435, -113.617, elevation 820 m, 26 Apr 2009, Rebman 17278 (SD).

U. S. A. Arizona: Gila County: Mazatzal Mountains: S wall of Barnhardt Canyon, 34.0917, -111.4357, elevation 1,350 m, 1 Jun 1983, Windham 446 (DUKE [known triploid]). Arizona: Gila County: Mazatzal Mountains: S wall of Barnhardt Canyon, 34.0917, -111.4357, elevation 1,350 m, 1 Jun 1983, Windham 447 (UT [known tetraploid]). Arizona: Graham County: 13 km SW of Swift Trail Junction: Pinaleno Moutains: Wet Canyon (Coronado National Forest), 32.65157, -109.81448, elevation 1,870 m, 5 May 2008, Schuettpelz 1231A (DUKE). Arizona: Graham County: Pinaleño Mountains: SE side of Jacobson Canyon, 32.6785, -109.7711, elevation 2,340 m, 28 Aug 1985, Windham 773 (UT [known tetraploid]). Arizona: Maricopa County: Mazatzal Mountains: Tributary of Sycamore Creek (Tonto National Forest), 33.93553, -111.48484, elevation 1,211 m, 10 May 2008, Schuettpelz 1240A (DUKE).

Inferred Hybrid Specimen Resembling this Species-U. S. A. Arizona: Graham County: $7 \mathrm{~km}$ SW of Swift Trail Junction: Pinaleno Moutains: Jacobson Canyon (Coronado National Forest), 32.68347, -109.76332, elevation 1,272 m, 5 May 2008, Schuettpelz 1229A (DUKE).

Pentagramma pallida (Weath.) Yatsk., Windham \& E. Wollenw., Amer. Fern J. 80: 15. 1990. Pityrogramma triangularis (Kaulf.) Maxon var. pallida Weath., Rhodora 22: 119. 1920. Pityrogramma pallida (Weath.) K. S. Alt \& V. E. Grant, Brittonia 12: 168. 1960.-TYPE: U. S. A.: California, Madera County: Hills about three miles above Pollasky, 11 Apr 1906, Heller 8141 (holotype: GH! [barcode 00023173]; isotypes: DS [ploidy level not assessed], MO!).

Distribution-Restricted to the western foothills of the Sierra Nevada of California in the U. S. A.

Conservation Assessment-This species has a relatively broad distribution (extent of occurrence estimated to be about $40,000 \mathrm{~km}^{2}$ ) and many populations. It is assessed to be of least concern (LC).

Notes - Spores were measured from the holotype and one isotype (we did not examine the DS isotype). Both were inferred to be diploid (Fig. 1), and we have found no evidence indicating that P. pallida has been involved in the origin of any polyploid taxon or individual.

Additional Inferred Diploid Specimens-U. S. A. California: Butte County: Chico: Upper Bidwell Park: along Big Chico Creek, between Diversion Dam and Salmon Hole, 39.77900, -121.74800, elevation 111 m, 21 May 2008, Schuettpelz 1350A (DUKE). California: Kern County: NE of Bakersfield near Cow Flat Creek in Kern River Canyon ca. 1.55 km SW of Democrat Spring, 35.49972, -118.69389, elevation 549 m, 28 Apr 2006, Windham 3433 (DUKE). California: Mariposa County: $2 \mathrm{~km} \mathrm{~W}$ of El Portal: off of CA-140: Merced Gorge (Sierra National Forest), 37.66830, -119.80443, elevation 562 m, 19 May 2008, Schuettpelz 1327A (DUKE). 
Pentagramma rebmanii (Winner \& M. G. Simpson) Schuettp. \& Windham, comb. et stat. nov. Pentagramma triangularis (Kaulf.) Yatsk., Windham \& E. Wollenw. subsp. rebmanii Winner \& M. G. Simpson, Madroño 54: 345. 2007.-TYPE: U. S. A.: California, San Diego County: Cleveland National Forest: Pine Creek Wilderness: north of Barrett Lake and south of Descanso, east of Japatul Valley Road, southeast of Horsethief Canyon Trailhead and just west of Pine Valley Creek, northfacing slope, 32.7442, -116.6533, elevation 610 m, 23 Mar 2005, Rebman 11483 (holotype: SD! [accession 159328]; isotypes: BCMEX [ploidy level not assessed], RSA!, UC [ploidy level not assessed]).

Distribution-Known only from southwestern California (apparently restricted to San Diego County) and northwestern Baja California.

Conservation Assessment-This species has a restricted distribution (extent of occurrence estimated to be about $8,000 \mathrm{~km}^{2}$ ), but some populations are situated in protected areas. It is assigned a preliminary conservation status of near threatened (NT).

Notes-Spores were measured from the holotype and one isotype (we did not examine the BCMEX and UC isotypes); we inferred both specimens to be diploid (Fig. 1). One inferred polyploid, with larger average spore size but morphology similar to $P$. rebmanii, was found. This polyploid specimen is listed separately below, following the inferred diploid specimens.

Additional Inferred Diploid Specimens-U. S. A. California: San Diego County: $15 \mathrm{~km}$ SE of Alpine: intersection of Espinosa Creek and Pine Valley Creek (Cleveland National Forest), 32.74433, -116.65454, elevation 635 m, 13 May 2008, Schuettpelz 1257A (DUKE). California: San Diego County: $5 \mathrm{~km} \mathrm{E}$ of Boulevard: off of I-8: Walker Canyon (Walker Canyon Ecological Reserve), 32.66151, -116.20762, elevation 807 m, 12 May 2008, Schuettpelz 1247A (DUKE). California: San Diego County: Hauser Canyon Wilderness Area (USFS property), $\mathrm{N}$ of Hauser Mountain: SW of Morena Lake and NW of Cameron Corners: on a lower N-facing slope along Hauser Creek, 32.6714, -116.5697, elevation 560 m, 9 Mar 2003, Rebman 8919 (MO).

Inferred Polyploid Specimen Resembling this SpeciesU. S. A. California: San Diego County: above Campo Creek along old alignment of CA Highway 94, 32.60694, -116.47667, elevation 770 m, 24 Apr 2006, Metzgar 171 (DUKE).

Pentagramma triangularis (Kaulf.) Yatsk., Windham \& E. Wollenw., Amer. Fern J. 80: 15. 1990. Gymnogramma triangularis Kaulf., Enum. Filic. 73. 1824. Ceropteris triangularis (Kaulf.) Underw., Bull. Torrey Bot. Club 29: 630. 1902. Pityrogramma triangularis (Kaulf.) Maxon, Contr. U. S. Natl. Herb. 17: 173. 1913.—TYPE: U. S. A.: California, 1816, Chamisso s. n. (holotype: B! [barcode B 20 0090557]).

Distribution-Broadly distributed throughout the westernmost portion of North America, from British Columbia in Canada to Baja California in Mexico. In the U. S. A., the species is found in California, Idaho, Nevada, Oregon, Utah, and Washington.

Conservation Assessment-This species has a broad distribution (extent of occurrence estimated to be over 1,000,000 $\mathrm{km}^{2}$ ), with many populations situated protected areas. It is assessed to be of least concern (LC).
Notes-Spores were measured from the holotype, which we inferred to be diploid (Fig. 1). As discussed in the main text, morphologically indistinguishable polyploids with larger average spore sizes are commonly encountered. Putative polyploids present in our sample are listed separately below, following the inferred or known diploid specimens.

Additional Inferred or Known Diploid Specimens-U. S. A. California: Butte County: $1 \mathrm{~km}$ SE of Feather Falls: along upper route of Feather Falls National Scenic Trail (Plumas National Forest), 39.63599, -121.26615, elevation 544 m, 20 May 2008, Schuettpelz 1347A (DUKE). California: Butte County: $20 \mathrm{~km}$ NE of Oroville: Big Bald Rock (Plumas National Forest), 39.64533, -121.34321, elevation 964 m, 21 May 2008, Schuettpelz 1358A (DUKE). California: Butte County: 9 km N of Oroville: North Table Mountain: Beatson Hollow (North Table Mountain Ecological Reserve), 39.59535, -121.55133, elevation 409 m, 21 May 2008, Schuettpelz 1364A (DUKE). California: Butte County: Chico: Upper Bidwell Park: along Big Chico Creek, between Diversion Dam and Salmon Hole, 39.78157, -121.74615, elevation 121 m, 21 May 2008, Schuettpelz 1353A (DUKE). California: Butte County: Near Feather Falls: along overlook spur of Feather Falls National Scenic Trail (Plumas National Forest), 39.64168, -121.27385, elevation 615 m, 20 May 2008, Schuettpelz 1346A (DUKE). California: Kern County: NE of Bakersfield near Cow Flat Creek in Kern River Canyon ca. 1.57 km SW of Democrat Spring, 35.49972, -118.69417, elevation 556 m, 28 Apr 2006, Windham 3431 (DUKE). California: Los Angeles County: N of Azusa along West Fork of the San Gabriel River, 34.2413, -117.8704, elevation 470 m, 1 Apr 1998, Windham 98-101 (UT [known diploid]). California: Los Angeles County: N of San Fernando: along Sand Canyon Road: between CA-14 and I-210 (Angeles National Forest), 34.36076, -118.39161, elevation 819 m, 15 May 2008, Schuettpelz 1282A (DUKE). California: Los Angeles County: Santa Monica Mountains, along Arroyo Sequit, 34.0647, -118.9326, elevation 65 m, 1 Apr 1998, Windham 98-108 (UT [known diploid]). California: Mariposa County: $2 \mathrm{~km} \mathrm{~W}$ of El Portal: off of CA-140: Merced Gorge (Sierra National Forest), 37.66802, -119.80458, elevation 555 m, 19 May 2008, Schuettpelz 1332A (DUKE). California: Monterey County: Santa Lucia Mountains: along Nacimiento Fergusson Road: $1 \mathrm{~km}$ E of Pacific Ocean: above Kirk Creek (Los Padres National Forest), 35.99529, -121.48584, elevation 314 m, 18 May 2008, Schuettpelz 1317A (DUKE). California: Monterey County: Santa Lucia Mountains: along Nacimiento Fergusson Road: $1 \mathrm{~km}$ E of Pacific Ocean: above Kirk Creek (Los Padres National Forest), 35.99553, -121.48687, elevation 306 m, 18 May 2008, Schuettpelz 1316A (DUKE). California: Orange County: Cleveland National Forest: side canyon of Hot Springs Canyon, 33.60361, -117.5075, elevation 297 m, 25 Apr 2006, Metzgar 179 (DUKE). California: Orange County: Santa Ana Mountains, along tributary of Hot Spring Canyon, 33.6028, -117.5086, elevation 255 m, 31 Mar 1998, Windham 98-096 (UT [known diploid]). California: Riverside County: $11 \mathrm{~km}$ E of Valle Vista: off of CA-74: S Fork of San Jacinto River, near intersection with Dry Creek (San Bernardino National Forest), 33.70902, -116.78321, elevation 798 m, 14 May 2008, Schuettpelz 1277A (DUKE). California: San Diego County: $15 \mathrm{~km}$ SE of Alpine: intersection of Espinosa Creek and Pine Valley Creek (Cleveland National Forest), 32.74438, -116.65335, elevation 622 m, 13 May 2008, Schuettpelz 1254A (DUKE). California: Tehama County: SW corner of Ponderosa Sky Ranch housing development, 40.3419, -121.7886, elevation 945 m, 14 Jun 1984, Ranker 753 (UT [known 
diploid]). California: Trinity County: Gray Falls Campground, along Highway 299 and Trinity River, 40.8578, -123.4917, elevation 300 m, 19 Jun 1984, Ranker 754 (UT [known diploid]). Nevada: Clark County: BLM lands: Newberry Mountains: Christmas Tree Pass, 35.2633, -114.7596, elevation 1193 m, 16 May 2008, Beck 1098 (DUKE). Oregon: Lane County: above Sea Lion Caves along US Route 101, 44.1223, -124.1263, elevation 105 m, 16 Jun 1986, Windham 836 (UT [known diploid]). Oregon: Linn County: Horse Rock Ridge, SW of Crawfordsville, 44.2976, -122.875, elevation 775 m, 19 May 2006, Pryer 06-01 (DUKE). Utah: Washington County: Zion National Park: near Emerald Falls, 37.25783, -112.96659, elevation 1,552 m, 4 Apr 2009, Smith 9 (DUKE).

Inferred Polyploid Specimens Resembling this SpeciesU. S. A. California: Santa Barbara County: Santa Cruz Island: along trail between Prisoners Harbor and Pelican Bay, 34.03178, -119.70109, elevation 4 m, 17 May 2008, Schuettpelz 1302A (DUKE). California: Santa Barbara County: Santa Cruz Island: Cañada del Puerto (between Prisoners Harbor and Main Ranch), 34.00149, -119.71449, elevation 58 m, 16 May 2008, Schuettpelz 1298A (DUKE). California: Santa Barbara County: Santa Cruz Island: Cañada del Puerto (between Prisoners Harbor and Main Ranch), 34.00659, -119.69948, elevation 31 m, 16 May 2008, Schuettpelz 1291A (DUKE). California: Santa Barbara County: Santa Ynez Moutains: off of Stagecoach Road: $2 \mathrm{~km}$ NW of intersection with Camino Cielo: Cold Spring Canyon (Los Padres National Forest), 34.52184, -119.83929, elevation 502 m, 18 May 2008, Schuettpelz 1312A (DUKE).

Pentagramma viscosa (Nutt. ex D. C. Eaton) Schuettp. \& Windham, comb. nov. Gymnogramma viscosa Nutt. ex D. C. Eaton, Ferns N. Amer. 2: 16. 1879. Ceropteris viscosa (Nutt. ex D. C. Eaton) Underw., Bull. Torrey Bot. Club 29: 631. 1902. Pityrogramma viscosa (Nutt. ex D. C. Eaton) Maxon, Contr. U. S. Natl. Herb. 17: 173. 1913. Pityrogramma triangularis (Kaulf.) Maxon var. viscosa (Nutt. ex D. C. Eaton) Weath., Rhodora 22: 117. 1920. Pentagramma triangularis (Kaulf.) Yatsk., Windham \& E. Wollenw. subsp. viscosa (Nutt. ex D. C. Eaton) Yatsk., Windham \& E. Wollenw., Amer. Fern J. 80: 15. 1990.TYPE: U. S. A. California: San Diego County, Nuttall s. n. (holotype: PH! [accession 1085482]).

Distribution-Confined to coastal southwest California (including the Channel Islands) and northwest Baja California.

Conservation Assessment-This species has a relatively broad distribution (extent of occurrence estimated to be over $100,000 \mathrm{~km}^{2}$ ) and many populations. It is assessed to be of least concern (LC).

Notes-Spores were measured from the holotype, which we inferred to be diploid (Fig. 1). As discussed in the main text, we have encountered no putative polyploids with morphology similar to $P$. viscosa.

Additional Inferred Diploid Specimens-U. S. A. California: San Diego County: ravine along Del Dios Highway below Lake Hodges, 33.0436, -117.14861, elevation 61 m, 25 Apr 2006, Metzgar 172 (DUKE). California: Santa Barbara County: Santa Cruz Island: Cañada del Puerto (between Prisoners Harbor and Main Ranch), 34.00149, -119.71449, elevation 58 m, 16 May 2008, Schuettpelz 1297A (DUKE). California: Santa Barbara County: Santa Cruz Island: Cañada del Puerto (between Prisoners Harbor and Main Ranch), 34.00659, -119.69948, elevation 31 m, 16 May 2008, Schuettpelz 1284A (DUKE). California: Santa Barbara County: Santa Cruz Island: Cañada del Puerto (between Prisoners Harbor and Main Ranch), 34.00659, -119.69948, elevation 31 m, 16 May 2008, Schuettpelz 1287A (DUKE). California: Santa Barbara County: Santa Cruz Island: Cañada del Puerto (between Prisoners Harbor and Main Ranch), 34.00659, -119.69948, elevation 31 m, 16 May 2008, Schuettpelz 1290A (DUKE).

AcKnowledgments. We thank the California Department of Fish and Game, the City of Chico, the United States Forest Service, and the United States National Park Service for permission to collect specimens for this research. We are also grateful to James Beck, Jordan Metzgar, Tom Ranker, Jon Rebman, Carl Rothfels, and Scott Smith for access to their collections, and to Amanda Grusz, Layne Huiet, Erin Sigel, Michael Simpson, Annette Winner, and George Yatskievych for their help and feedback. Alice Tangerini prepared the beautiful illustration of Pentagramma glanduloviscida and Gary Krupnick provided invaluable assistance in assessing the conservation status of the recognized species. Two anonymous reviewers, the Associate Editor, and the Editor-in-Chief all provided useful comments. Funding for this research was provided in part by the Hunt Institute for Botanical Documentation and the United States National Science Foundation (DEB-0717398 and DEB-1405181).

\section{Literature Cited}

Abramoff, M. D., P. J. Magelhaes, and S. J. Ram. 2004. Image processing with ImageJ. Biophotonics International 11: 36-42.

Akaike, H. 1974. A new look at the statistical model identification. IEEE Transactions on Automatic Control 19: 716-723.

Alt, K. S. and V. Grant. 1960. Cytotaxonomic observations on the goldback fern. Brittonia 12: 153-170.

Bachman, S., J. Moat, A. W. Hill, J. de la Torre, and B. Scott. 2011. Supporting red list threat assessments with GeoCAT: Geospatial conservation assessment tool. ZooKeys 150: 117-126.

Barrington, D. S., C. A. Paris, and T. A. Ranker. 1986. Systematic inferences from spore and stomate size in the ferns. American Fern Journal 76: 149-159.

Beck, J. B., M. D. Windham, G. Yatskievych, and K. M. Pryer. 2010. A diploids-first approach to species delimitation and interpreting polyploid evolution in the fern genus Astrolepis (Pteridaceae). Systematic Botany 35: 223-234.

Cracraft, J. 1983. Species concepts and speciation analysis. Current Ornithology 1: 159-187.

de Queiroz, K. 1998. The general lineage concept of species, species criteria, and the process of speciation: a conceptual unification and terminological recommendations. Pp. 57-75 in Endless forms: Species and speciation, eds. D. J. Howard and S. H. Berlocher. New York: Oxford University Press.

de Queiroz, K. 2007. Species concepts and species delimitation. Systematic Biology 56: 879-886.

Dobzhansky, T. 1970. Genetics of the evolutionary process. New York: Columbia University Press.

Donoghue, M. J. 1985. A critique of the biological species concept and recommendations for a phylogenetic alternative. The Bryologist 88 172-181.

Dyer, R. J., J. Pellicer, V. Savolainen, I. J. Leitch, and H. Schneider. 2013. Genome size expansion and the relationship between nuclear DNA content and spore size in the Asplenium monanthes fern complex (Aspleniaceae). BMC Plant Biology 13: 219.

Eaton, D. C. 1879. The ferns of North America. Colored figures and descriptions, with synonymy and geographical distribution, of the ferns (Including the Ophioglossaceae) of the United States of America and the British North American Possessions. Boston: S. E. Cassino.

Eiserhardt, W. L., J. G. Rohwer, S. J. Russell, J. C. Yesilyurt, and H. Schneider. 2011. Evidence for radiations of cheilanthoid ferns in the Greater Cape Floristic Region. Taxon 60: 1269-1283.

Felsenstein, J. 1985. Confidence limits on phylogenies: An approach using the bootstrap. Evolution 39: 783-791.

Gastony, G. J. and D. R. Rollo. 1998. Cheilanthoid ferns (Pteridaceae: Cheilanthoideae) in the southwestern United States and adjacent Mexico-a molecular phylogenetic reassessment of generic lines. Aliso 17: 131-144. 
Gastony, G. J. and G. Yatskievych. 1992. Maternal inheritance of the chloroplast and mitochondrial genomes in cheilanthoid ferns. American Journal of Botany 79: 716-722.

Grusz, A. L., M. D. Windham, and K. M. Pryer. 2009. Deciphering the origins of apomictic polyploids in the Cheilanthes yavapensis complex (Pteridaceae). American Journal of Botany 96: 1636-1645.

Guindon, S. and O. Gascuel. 2003. A simple, fast, and accurate algorithm to estimate large phylogenies by maximum likelihood. Systematic Biology 52: 696-704.

Hess, P. N. and C. A. De Moraes Russo. 2007. An empirical test of the midpoint rooting method. Biological Journal of the Linnean Society. Linnean Society of London 92: 669-674.

Howell, J. T. 1962. New varieties of western plants-IV. Leaflets of Western Botany 9: 223-224.

Huelsenbeck, J. P., J. P. Bollback, and A. M. Levine. 2002. Inferring the root of a phylogenetic tree. Systematic Biology 51: 32-43.

IUCN. 2012. IUCN red list categories and criteria: Version 3.1. Second edition. Gland and Cambridge: IUCN.

Kaulfuss, G. F. 1824. Enumeratio Filicum quas in Itinere Circa Terram Legit $\mathrm{Cl}$. Adalbertus de Chamisso Adiectis in Omnia Harum Plantarum Genera Permultasque Species non Satis Cognitas vel Novas Animadversionibus. Lipsiae: Sumtibus Caroli Cnobloch.

Löve, Á., D. Löve, and R. E. G. Pichi Sermolli. 1977. Cytotaxonomical atlas of the Pteridophyta. Vaduz: Cramer.

Maddison, W. P., M. J. Donoghue, and D. R. Maddison. 1984. Outgroup analysis and parsimony. Systematic Zoology 33: 83-103.

Maddison, D. R. and W. P. Maddison. 2005. MacClade: Analysis of phylogeny and character evolution, version 4.08. Sunderland: Sinauer Associates.

Manton, I. and G. Vida. 1968. Cytology of the fern flora of Tristan da Cunha. Proceedings of the Royal Society of London. Series B, Biological Sciences 170: 361-379.

Maxon, W. R. 1913. Studies of tropical american ferns-no. 4. Contributions from the United States National Herbarium 17: 133-179.

Mayr, E. 1942. Systematics and the origin of species. New York: Columbia University Press.

Mickel, J. T. and A. R. Smith. 2004. The Pteridophytyes of Mexico. New York: New York Botanical Garden Press.

Mishler, B. D. 1985. The morphological, developmental, and phylogenetic basis of species concepts in bryophytes. The Bryologist 88: 207-214.

Nagalingum, N. S., H. Schneider, and K. M. Pryer. 2007. Molecular phylogenetic relationships and morphological evolution in the heterosporous fern genus Marsilea. Systematic Botany 32: 16-25.

Nixon, K. C. and Q. D. Wheeler. 1990. An amplification of the phylogenetic species concept. Cladistics 6: 211-223.

Posada, D. 2008. jModelTest: Phylogenetic model averaging. Molecular Biology and Evolution 25: 1253-1256.

Sanderson, M. J. and H. B. Shaffer. 2002. Troubleshooting molecular phylogenetic analyses. Annual Review of Ecology and Systematics 33: 49-72.

Schuettpelz, E. and S. B. Hoot. 2006. Inferring the root of Isoëtes: Exploring alternatives in the absence of an acceptable outgroup. Systematic Botany 31: 258-270.

Schuettpelz, E. and K. M. Pryer. 2007. Fern phylogeny inferred from 400 leptosporangiate species and three plastid genes. Taxon 56: 1037-1050.

Schuettpelz, E. and K. M. Pryer. 2009. Evidence for a Cenozoic radiation of ferns in an angiosperm-dominated canopy. Proceedings of the National Academy of Sciences USA 106: 11200-11205.

Schuettpelz, E., A. L. Grusz, M. D. Windham, and K. M. Pryer. 2008. The utility of nuclear gapCp in resolving polyploid fern origins. Systematic Botany 33: 621-629.

Schuettpelz, E., P. Korall, and K. M. Pryer. 2006. Plastid atpA data provide improved support for deep relationships among ferns. Taxon 55: 897-906.

Schuettpelz, E., H. Schneider, L. Huiet, M. D. Windham, and K. M. Pryer 2007. A molecular phylogeny of the fern family Pteridaceae: Assessing overall relationships and the affinities of previously unsampled genera. Molecular Phylogenetics and Evolution 44: 1172-1185.

Simmons, M. P. 2004. Independence of alignment and tree search. Molecular Phylogenetics and Evolution 31: 874-879.

Smith, D. M. 1980. Flavonoid analysis of the Pityrogramma triangularis complex. Bulletin of the Torrey Botanical Club 107: 134-145.

Smith, D. M., S. P. Craig, and J. Santarosa. 1971. Cytological and chemical variation in Pityrogramma triangularis. American Journal of Botany 58: 292-299.
Swofford, D. L. 2002. PAUP*. Phylogenetic analysis using parsimony (*and other methods) version 4.0 beta 10 . Sunderland: Sinauer Associates.

Takhtajan, A. 1986. Floristic regions of the world. Berkeley: University of California Press.

Walker, T. G. 1966. A cytotaxonomic survey of the Pteridophytes of Jamaica. Transactions of the Royal Society of Edinburgh 66: 169-237.

Walker, T. G. 1984. Chromosomes and evolution in pteridophytes. Pp. 101-141 in Chromosomes in evolution of eukaryotic groups Volume 2, eds. A. K. Sharma and A. Sharma. Boca Raton: CRC Press.

Weatherby, C. A. 1920. Varieties of Pityrogramma triangularis. Rhodora 22: 113-120.

Wheeler, W. C. 1990. Nucleic acid sequence phylogeny and random outgroups. Cladistics 6: 363-368.

Windham, M. D. and G. Yatskievych. 2003. Chromosome studies of cheilanthoid ferns (Pteridaceae: Cheilanthoideae) from the western United States and Mexico. American Journal of Botany 90: 1788-1800.

Windham, M. D., L. Huiet, E. Schuettpelz, A. L. Grusz, C. Rothfels, J. Beck, G. Yatskievych, and K. M. Pryer. 2009. Using plastid and nuclear DNA sequences to redraw generic boundaries and demystify species complexes in cheilanthoid ferns. American Fern Journal 99: 128-132.

Winner, A. L. and M. G. Simpson. 2007. A new subspecies of Pentagramma triangularis (Pteridaceae). Madroño 54: 345-353.

Wollenweber, E. and V. H. Dietz. 1980. Flavonoid patterns in the farina of goldenback ferns and silverback ferns. Biochemical Systematics and Ecology 8: 21-33.

Wollenweber, E. and D. M. Smith. 1981. The chemoidentity of the holotype of Pityrogramma triangularis. American Fern Journal 71: 120.

Wollenweber, E., V. H. Dietz, G. Schilling, J. Favre-Bonvin, and D. M. Smith. 1985. Flavonoids from chemotypes of the goldback fern, Pityrogramma triangularis. Phytochemistry 24: 965-971.

Wollenweber, E., V. H. Dietz, D. M. Smith, and D. S. Seigler. 1979. A novel C-methylated dihydrochalcone from Pityrogramma triangularis var. viscosa. Zeitschrift fuer Naturforschung 34: 876-877.

Yatskievych, G. and M. D. Windham. 1993. Pentagramma. Pp. 149-151 in Flora of North America, vol. 2, ed. Flora of North America Editorial Committee. New York: Oxford University Press.

Yatskievych, G., M. D. Windham, and E. Wollenweber. 1990. A reconsideration of the genus Pityrogramma (Adiantaceae) in western North America. American Fern Journal 80: 9-17.

Appendix 1. Specimens of Pentagramma included in our spore and/ or phylogenetic analyses. For each specimen, we first indicate its morphotype based on the taxa recognized in the most recent prior classification (Winner and Simpson 2007): $M=P$. triangularis subsp. maxonii; $\mathrm{P}=P$. pallida $; \mathrm{R}=P$. triangularis subsp. rebmanii; $\mathrm{S}=P$. triangularis subsp. semipallida $; \mathrm{T}=P$. triangularis subsp. triangularis; $\mathrm{V}=P$. triangularis subsp. viscosa. We also provide the morphotype for each specimen based on the current study: $\mathrm{G}=P$. glanduloviscida; $\mathrm{M}=P$. maxonii; $\mathrm{P}=P$. pallida; $\mathrm{R}=P$. rebmanii $; \mathrm{T}=P$. triangularis $; \mathrm{V}=P$. viscosa. Then, we list (as available) spore size mean \pm standard deviation $(\mu \mathrm{m})$, spore form $(\mathrm{N}=$ normal; $\mathrm{L}=$ malformed; $\mathrm{X}=$ mixed), atpA region, $\operatorname{trn} G-R$ region, and gapCp (short copy) segment GenBank accession numbers, and our taxonomic conclusion. See main text for rationale concerning conclusions summarized here. Complete voucher information for each specimen is provided in the main text (Taxonomic Treatment).

Beck 1098 (DUKE), T, T, $39.0 \pm 1.2, \mathrm{~N}, \mathrm{KR} 066337, \mathrm{KR} 132616$, KR132681/KR132682, diploid P. triangularis; Blumer 3271 (ARIZ), M, M, $41.5 \pm 2.0, \mathrm{~N},-$, - - -, diploid P. maxonii; Blumer 3271 (GH), M, M, $42.4 \pm$ 2.5, N, -, -, -, diploid P. maxonii; Blumer 3271 (MO), M, M, $43.5 \pm 2.3, \mathrm{X},-$, ,-- , autotetraploid resembling P. maxonii; Blumer 3271 (US), M, M, $40.4 \pm$ 2.4, N, -, -, -, diploid P. maxonii; Chamisso s.n. (B), T, T, $42.0 \pm 2.2, \mathrm{~N},-$, - - diploid P. triangularis; Heller $8141(\mathrm{GH}), \mathrm{P}, \mathrm{P}, 30.7 \pm 1.9, \mathrm{~N},-$ - - - -, diploid P. pallida; Heller $8141(\mathrm{MO}), \mathrm{P}, \mathrm{P}, 31.7 \pm 1.8, \mathrm{~N},-$, -, -, diploid P. pallida; Metzgar 171 (DUKE), R, R, $47.0 \pm 3.8$, X, KR066338, KR132617, KR132666/KR132667, allotetraploid resembling P. rebmanii; Metzgar 172 (DUKE), V, V, -, -, KR066339, KR132618, KR132668/KR132669, diploid P. viscosa; Metzgar 179 (DUKE), T, T, $35.2 \pm$ 1.9, N, KR066340, KR132619, KR132670/KR132671, diploid P. triangularis; Nuttall s.n. (PH), V, V, $42.5 \pm$ 1.3, N, -, -, -, diploid P. viscosa; Pryer 06-01 (DUKE), T, T, -, -, KR066341, KR132620, KR132675/KR132676, diploid P. triangularis; Ranker 753 (UT), S, T, $34.3 \pm 1.6$, N, - - -, -, diploid P. triangularis; Ranker 754 (UT), T, T, $39.6 \pm$ 1.2, N, -, -, -, diploid P. triangularis; Rebman 11483 (RSA), R, R, $36.8 \pm$ 1.1, N, -, -, -, diploid P. rebmanii; Rebman 11483 (SD), R, R, $37.6 \pm 2.0, \mathrm{~N}_{\text {, - , - }}$ 
-, diploid P. rebmanii; Rebman 13506 (SD), M, G, $38.1 \pm$ 1.7, N, KR066342, KR132621, KR132739/KR132740, diploid P. glanduloviscida; Rebman 14051 (SD), M, G, -, -, KR066343, KR132622, KR132741/KR132742/KR132743, autotetraploid resembling P. glanduloviscida; Rebman 17278 (SD), M, M, $42.7 \pm 2.1$, N, KR066344, KR132623, KR132744/KR132745, autotetraploid resembling P. maxonii; Rebman 8919 (MO), R, R, $39.7 \pm 2.6$, N, KR066345, KR132624, KR132677/KR132678, diploid P. rebmanii; Rothfels 2570 (DUKE), $\mathrm{M}, \mathrm{M}, 41.0 \pm 2.0, \mathrm{~N}, \mathrm{KR} 066346$, KR132625, KR132679/KR132680, diploid P. maxonii; Schuettpelz 1229A (DUKE), M, M, $42.4 \pm 1.8$, N, KR066347, KR132626, KR132683/KR132684, hybrid resembling P. maxonii; Schuettpelz 1231 A (DUKE), M, M, $44.2 \pm 1.8, \mathrm{~N}, \mathrm{KR} 066348, \mathrm{KR} 132627, \mathrm{KR} 132685 /$ KR132686, allotetraploid resembling P. maxonii; Schuettpelz 1240A (DUKE), M, M, $43.7 \pm 1.6$, N, KR066349, KR132628, KR132687/KR132688, allotetraploid resembling P. maxonii; Schuettpelz 1242A (DUKE), M, M, $40.0 \pm$ 1.7, N, KR066350, KR132629, KR132689, diploid P. maxonii; Schuettpelz 1247 A (DUKE), R, R, $40.3 \pm 1.3, \mathrm{~N}$, KR066351, KR132630, KR132690, diploid P. rebmanii; Schuettpelz 1254A (DUKE), T, T, $35.2 \pm 1.4$, N, KR066352, KR132631, KR132691, diploid P. triangularis; Schuettpelz 1257A (DUKE), R, R, $37.1 \pm 1.8$, N, KR066353, KR132632, KR132692/KR132693, diploid P. rebmanii; Schuettpelz 1264A (DUKE), M, G, $40.5 \pm 1.5$, N, KR066354, KR132633, KR132694/KR132695, diploid P. glanduloviscida; Schuettpelz 1266A (DUKE), M, G, $39.0 \pm 1.3$, N, KR066355, KR132634, KR132696/ KR132697, diploid P. glanduloviscida; Schuettpelz 1268A (DUKE), M, G, $52.4 \pm 1.7$, X, KR066356, KR132635, KR132698/KR132699, autotriploid resembling P. glanduloviscida; Schuettpelz 1269A (DUKE), M, G, $43.1 \pm$ 1.8, N, KR066357, KR132636, KR132700/KR132701, autotetraploid resembling P. glanduloviscida; Schuettpelz 1277A (DUKE), T, T, $36.7 \pm 1.3, \mathrm{~N}$, KR066358, KR132637, KR132702/KR132703, diploid P. triangularis; Schuettpelz $1282 A$ (DUKE), T, T, $41.4 \pm 1.7, \mathrm{~N}, \mathrm{KR} 066359, \mathrm{KR} 132638, \mathrm{KR} 132704$ / KR132705, diploid P. triangularis; Schuettpelz 1284A (DUKE), V, V, $34.8 \pm$ 1.6, N, KR066360, KR132639, KR132706, diploid P. viscosa; Schuettpelz 1287A (DUKE), V, V, $38.4 \pm 1.7, \mathrm{~N}, \mathrm{KR} 066361, \mathrm{KR} 132640, \mathrm{KR} 132707 /$ KR132708, diploid P. viscosa; Schuettpelz 1290A (DUKE), V, V, $39.3 \pm 1.3, \mathrm{~N}$, KR066362, KR132641, KR132709, diploid P. viscosa; Schuettpelz 1291A (DUKE), T, T, -, L, KR066363, KR132642, KR132710/KR132711/KR132712, allotriploid resembling P. triangularis; Schuettpelz 1297A (DUKE), V, V, $37.4 \pm 1.3, \mathrm{~N}, \mathrm{KR} 066364, \mathrm{KR} 132643, \mathrm{KR} 132713 / \mathrm{KR} 132714$, diploid
P. viscosa; Schuettpelz 1298A (DUKE), T, T, $49.4 \pm 1.5, \mathrm{~N}, \mathrm{KR} 066365$, KR132644, KR132715/KR132716, autohexaploid resembling P. triangularis; Schuettpelz 1302A (DUKE), T, T, $49.5 \pm 1.7$, N, KR066366, KR132645, KR132717/KR132718, autohexaploid resembling P. triangularis; Schuettpelz 1312A (DUKE), T, T, $47.9 \pm 1.6, \mathrm{~N}, \mathrm{KR} 066367, \mathrm{KR} 132646, \mathrm{KR} 132719 /$ KR132720, autotetraploid resembling P. triangularis; Schuettpelz 1316A (DUKE), T, T, $40.1 \pm 1.5, \mathrm{~N}, \mathrm{KR} 066368, \mathrm{KR} 132647$, KR132721, diploid P. triangularis; Schuettpelz 1317A (DUKE), T, T, $39.9 \pm 1.9, \mathrm{~N}$, KR066369, KR132648, KR132722, diploid P. triangularis; Schuettpelz 1327A (DUKE) P, P, $35.5 \pm$ 1.1, N, KR066370, KR132649, KR132723/KR132724, diploid P. pallida; Schuettpelz 1332A (DUKE), T, T, $31.8 \pm 1.9$, N, KR066371, KR132650, KR132725/KR132726, diploid P. triangularis; Schuettpelz 1346A (DUKE), S, T, $39.8 \pm 1.3, \mathrm{~N}$, KR066372, KR132651, KR132727, diploid P. triangularis; Schuettpelz 1347A (DUKE), T, T, $39.4 \pm 1.7$, N, KR066373, KR132652, KR132728, diploid P. triangularis; Schuettpelz 1350A (DUKE), P, P, -, -, KR066374, KR132653, KR132729/KR132730, diploid P. pallida; Schuettpelz 1353A (DUKE), T, T, $33.9 \pm 2.0$, N, KR066375, KR132654, KR132731/KR132732, diploid P. triangularis; Schuettpelz 1358A (DUKE), S, T, $37.9 \pm 1.3$, N, KR066376, KR132655, KR132733/KR132734, diploid P. triangularis; Schuettpelz 1364A (DUKE), T, T, $40.1 \pm 1.9$, X, KR066377, KR132656, KR132735/KR132736, diploid P. triangularis; Schuettpelz 445 (DUKE), M, M, $41.3 \pm$ 1.4, N, KR066378, KR132657, KR132662/KR132663, diploid P. maxonii; Schuettpelz 473 (DUKE), M, M, $38.1 \pm 1.2$, N, KR066379, KR132658, KR132664/KR132665, diploid P. maxonii; Smith 9 (DUKE), T, T, -, -, KR066380, KR132659, KR132737/KR132738, diploid P. triangularis, Windham 337 (UT), M, M, $40.5 \pm 1.5$, N, - - - - - diploid P. maxonii; Windham 3431 (DUKE), T, T, $38.4 \pm 1.5, \mathrm{~N}$, KR066381, KR132660, KR132673/ KR132674, diploid P. triangularis; Windham 3433 (DUKE), P, P, -, -, KR066382, KR132661, KR132672, diploid P. pallida; Windham 446 (DUKE), M, M, $49.0 \pm$ 3.1, X, - - - -, autotriploid resembling P. maxonii; Windham 447 (UT), M, M, $45.2 \pm 1.5, \mathrm{~N},-,-,-$, , autotetraploid resembling P. maxonii; Windham 773 (UT), $\mathrm{M}, \mathrm{M}, 42.6 \pm 2.7, \mathrm{~N},-,-,-$, autotetraploid resembling P. maxonii; Windham 836 (UT), T, T, $40.7 \pm 2.3$, N, - - - - - diploid P. triangularis; Windham 98-084 (UT), M, G, $33.8 \pm 1.9$, N , - - - - , diploid P. glanduloviscida; Windham 98-096 (UT), T, T, $33.9 \pm 1.3$, N, -, -, -, diploid P. triangularis; Windham 98-101 (UT), T, T, $37.2 \pm 1.1, \mathrm{~N},-,-,-$, diploid P. triangularis; Windham 98-108 (UT), T, T, $38.1 \pm 1.4, \mathrm{~N},-,-,-$, diploid P. triangularis. 